Article

\title{
Impact of Oxygenated Additives on Soot Properties during Diesel Combustion
}

\author{
Natascia Palazzo ${ }^{1,2}$, Lars Zigan ${ }^{1,2}$ D, Franz J. T. Huber ${ }^{1,2}$ and Stefan Will 1,2,*(D) \\ 1 Lehrstuhl für Technische Thermodynamik (LTT), Friedrich-Alexander-Universität Erlangen-Nürnberg (FAU), \\ 91058 Erlangen, Germany; palazzo.natascia@gmail.com (N.P.); lars.zigan@fau.de (L.Z.); \\ franz.huber@fau.de (F.J.T.H.) \\ 2 Erlangen Graduate School in Advanced Optical Technologies (SAOT), \\ Friedrich-Alexander-Universität Erlangen-Nürnberg (FAU), 91052 Erlangen, Germany \\ * Correspondence: stefan.will@fau.de; Tel.: +49-9131-85-29900
}

Citation: Palazzo, N.; Zigan, L.;

Huber, F.J.T.; Will, S. Impact of Oxygenated Additives on Soot Properties during Diesel Combustion. Energies 2021, 14, 147. https:// doi.org/10.3390/en14010147

Received: 8 December 2020 Accepted: 23 December 2020 Published: 29 December 2020

Publisher's Note: MDPI stays neutral with regard to jurisdictional clai$\mathrm{ms}$ in published maps and institutional affiliations.

Copyright: (C) 2020 by the authors. Licensee MDPI, Basel, Switzerland. This article is an open access article distributed under the terms and conditions of the Creative Commons Attribution (CC BY) license (https:// creativecommons.org/licenses/by/ $4.0 /)$.

\begin{abstract}
Emissions from diesel engines can be limited and potentially decreased by modifying the fuel chemical composition through additive insertion. One class of additives that have shown to be particularly efficient in the reduction of the particulates from the combustion of diesel fuels are oxygenated compounds. In the present study we investigate the effect of tripropylene glycol methyl ether (TPGME) and two polyoxymethylene dimethyl ethers (POMDME or OMEs) on soot formation in a laminar diesel diffusion flame. From the evaluation of soot volume fraction by laser-induced incandescence (LII) measurements we could observe that OME additives have a substantial capability (higher compared to TPGME) to decrease the particle concentration, which drops by up to 36\% with respect to the pure diesel fuel. We also note a reduction in particle aggregate size, determined by wide-angle light scattering (WALS) measurements, which is more pronounced in the case of OME-diesel blends. The effects we observe can be correlated to the higher amount of oxygen content in the OME molecules. Moreover, both additives investigated seem to have almost no impact on the local soot temperature which could in turn play a key role in the production of soot particles.
\end{abstract}

Keywords: fuel additives; laser-induced incandescence; elastic light scattering; flame temperature; pre-vaporized diesel combustion

\section{Introduction}

Environmental particulate matter (PM) is considered a serious hazard for human health because of its harmful impact on the respiratory system. Fine particles $\mathrm{PM}_{2.5}$ (diameter $<2.5 \mu \mathrm{m}$ ) and ultra-fine particles $\mathrm{PM}_{0.1}$ (diameter $<0.1 \mu \mathrm{m}$ ) can easily penetrate into the lungs leading to chronic lung diseases such as asthma and lung cancer [1,2]. Besides the health risks, PM, which is mainly constituted of carbonaceous material called soot, can affect earth's climate change. Soot particles strongly absorb light in the visible spectrum influencing cloud formation and accelerating snow and ice melt [3]. Soot is emitted from a variety of combustion processes of carbon-based fuels when the amount of oxygen available is insufficient for complete combustion [3]. A well-known case is the non-stoichiometric combustion occurring in the diesel engine that usually generates a considerable amount of soot. Several strategies have been assessed to improve the efficiency of diesel engines and minimize the emissions of PM to meet the future regulation targets. An encouraging solution found is the insertion of fuel additives into the diesel fuel [4]. The term fuel additive generally refers to any substance added to the fuel capable of altering the fuel's physical and chemical properties [4]. Numerous studies have been carried out on the impact of different kinds of additives on diesel injector flow, spray and soot formation [5]. The species utilized as additives range from water to various metal-based substances, detergents as well as lubricants [6,7]. For example, detergents (i.e., polyether amines, imidazolines, fatty acid succinimides, polyether amines, etc.) are one of the most important 
components in a diesel additive package. These species are able to suppress deposit formation leading to a reduction in injector ageing and thus decreasing soot formation during long-term operation $[7,8]$. For direct soot reduction purposes, the most common additives investigated are oxygenated species such as mono-alkyl esters, long-chain fatty acids, n-butanol or methanol [9-11]. It has been observed that an increase in the fuel's oxygen content causes a decrease in soot emissions $[12,13]$. This phenomenon could be related to the suppression of $\mathrm{C}-\mathrm{C}$ bonds and, consequently, to soot precursors. Moreover, higher oxygen contents in the fuel structure supply more oxygen to burn carbon [13]. A number of studies have revealed that the addition of biodiesel or in general different alcohol/ester profiles leads to a slight increase in $\mathrm{NO}_{x}$ pollutants $[14,15]$. Besides oxygen content, the influence of the additive's molecular structure on the emission behavior of the fuel should also be considered. Ethers for instance may have a lower sooting tendency compared to alcohols [16]. Recent studies performed inside or at the exhaust of diesel engines highlight the tendency of some ether compounds, namely glycol ethers and longchain oxymethylene dimethyl ethers (OMEs), to efficiently act as soot reducers [17-19]. These species have densities similar to that of diesel and are toxicologically uncritical. Yet, as they are currently only available in small quantities they could only be used as an additive and not as a diesel surrogate. To develop a low-cost additized fuel suitable for diesel engines with reduced soot emission performances, it is necessary to understand the impact of oxygenated molecules on soot formation and sooting properties. Several empirical, semi-empirical and detailed emission models on diesel fuel combustion have been published [12,20-22]. However, the mechanism behind soot formation from diesel fuel as well as the effect of additives (e.g., on particle size), influenced also by the molecular structure and physical parameters connected to the engine (e.g., injection pressure, spray characteristics, engine temperature and pressure), are not completely understood. In this study we investigate the effect of oxygenated species on the soot volume fraction and soot aggregate size in a laminar diesel diffusion flame. This environment provides simplified conditions, where physical effects typical for an engine are bypassed and the influence of the chemical structure of the blended fuel on particle formation can be isolated. Moreover, the flame produced to this end is easily accessible for the use of laser-based diagnostics. In this work, laser-induced incandescence (LII) [23] and wide-angle light scattering (WALS) [24] are employed for the determination of soot volume fraction and radii of gyration of soot aggregates, respectively. Additionally, we performed flame temperature measurements using two-color pyrometry $[25,26]$, as additives potentially could affect the combustion temperature which, in turn, could influence soot formation. The additives investigated in this work are tripropylene glycol methyl ether (TPGME) and two poly oxymethylene dimethyl ethers (POMDME or OMEs with the chemical structure $\left.\mathrm{CH}_{3}-\mathrm{O}-\left(\mathrm{CH}_{2}-\mathrm{O}\right)_{n}-\mathrm{CH}_{3}\right)$. Here, specifically $\mathrm{OME}_{2}$ (meaning two $\mathrm{CH}_{2}$-O groups) and $\mathrm{OME}_{3-5}$ (a mixture of OMEs containing three, four and five $\mathrm{CH}_{2}-\mathrm{O}$ groups) were employed. The additives were inserted with varying concentrations of $1 \%, 3 \%$ and $9 \%$ in volume in a bare standard diesel fuel. The results obtained for the additised fuels are compared with those found for the pure standard diesel, with no additives, here called baseline for simplicity. The results can be used as dataset for the validation of diesel soot models, where usually the chemical structure of the fuel is one of the most important input parameters and plays a key role in the model's outcome.

\section{Theory: Influence of Additives on Soot Formation and Techniques for Soot Characterization}

Soot can be defined as a solid carbonaceous substance constituted by roughly eight parts of carbon and one part of hydrogen with a density of about $1.85 \mathrm{~g} / \mathrm{cm}^{3}$ [27], exhibiting a fractal-like geometry. The aggregates, whose size is usually in the sub-micron range [28], are constituted by almost spherical soot primary particles. As already mentioned, soot is generated by incomplete combustion of organic substances. In urban areas it is mainly produced as a result of fuel-rich combustion in engines. The formation of soot, i.e., a gaseous-solid phase transition which converts hydrocarbon molecules into 
carbonaceous clusters, is an extremely complex process, which has been widely discussed in the literature [28-32]. For the purposes of this work, we will focus the attention especially on the impact of oxygenated compounds on the fuel's sooting tendency.

\subsection{Effect of Oxygenated Species on Soot Formation and Oxidation}

The oxygenated compounds inserted into diesel fuel do not only modify the oxygen content but also other properties like the cetane number, density or viscosity. All these parameters could affect the fuel ignition time and the spatial distribution of the injected fuel in the chamber or cylinder which could in turn have an influence on PM emissions. Nevertheless, the increase in the oxygen content is believed to be the mainly responsible cause for the reduction in PM. Imtenan et al. [33] studied the relation between oxygen content and emissions characteristics and found that the degree of correlation between the emissions reduction capability of an additive and its oxygen content is considerably high $\left(R^{2}=0.95\right)$. Another crucial factor to take into account is the impact of the chemical structure of the oxygenated additive. A number of studies show that the ester structure of the biodiesel-diesel blend leads to higher smoke emissions than alcohol-diesel or ether-diesel blends [34,35]. Several studies report significant PM reduction compared to pure diesel combustion by using ethanol-diesel, dimethylglyoxime-ethanol-diesel blends [34,36-39] and alcohol fumigation into the inlet manifold [40-42]. A massive decrease in PM emissions has been noted when dimethyl ether (DME) is employed as additive [43,44]. The lower PM emissions of the DME-diesel blend, which has been observed under different engine operating conditions, was linked to the lack of C-C bonds of the DME which yields to a partially soot-free combustion. Following to that, many other ether-based compounds, with longer chains, higher oxygen content and a lower number of $\mathrm{C}-\mathrm{C}$ bonds, have been investigated as diesel additives. Two species stood out as very effective soot suppressors, namely TPGME and POMDME or OMEs, which we selected as diesel additives in this study.

\subsection{The Role of TPGME and OMES}

Tripropylene glycol methyl ether or TPGME, whose chemical structure is shown in Figure 1a, has recently been proposed as a viable soot reducing additive. Experiments in a constant-volume combustion vessel and in a single-cylinder direct injection diesel engine conducted by Mueller et al. [45] have revealed a higher soot reduction efficiency of this compound compared to other oxygenates. Using a detailed chemical kinetic model, Westbrook et al. [46] described the phenomenon of soot suppression in diesel engines, when an oxygenated hydrocarbon, including TPGME, is inserted to the fuel. According to this kinetic model, the suppression of soot observed experimentally in the case of oxygenate addition is connected to the decrease in the amount of soot precursor species present in the hot products of a fuel-rich diesel ignition zone. The general chemical structure of OMEs, shown in Figure $1 \mathrm{~b}$, is $\mathrm{CH}_{3}-\mathrm{O}-\left(\mathrm{CH}_{2}-\mathrm{O}\right)_{n}-\mathrm{CH}_{3}$, where $n$ can vary between one and seven (the most common OMEs have $n$ between two and five) $[17,19]$. The mass fraction of oxygen in these molecules reaches up to $50 \%$. The simplest molecule of OMEs is dimethoxymethane (DMM) with the molecular structure $\mathrm{CH}_{3}-\mathrm{O}-\mathrm{CH}_{2}-\mathrm{O}-\mathrm{CH}_{3}$, differing from DME only by one-O- $\mathrm{CH}_{2}-$ unit. Kenney et al. [47] and Sirman et al. [48] investigated PM emissions from a diesel blend with 15\% DMM in a direct injection diesel engine. In both studies a reduction in PM emission due to DMM addition was observed. Kenney et al. [47] remark though that, besides modification of the fuel by DMM addition, collective improvements of engine design, such as an after-treatment system, calibration strategy etc., have to be adopted to meet the future emission limits. An alternative to DMM, which is characterized by a low viscosity, a low boiling point $\left(42^{\circ} \mathrm{C}\right)$ and a different cetane number (30) than diesel, is the use of OMEs with $n$ ranging between two and five. These OMEs have properties similar to diesel, i.e., a higher boiling point and viscosity, which allows them to be blended with diesel in any percentage without requiring significant modifications of the engine's injection system. Pellegrini et al. [49] evaluated the emission performance of pure OMEs and a 10\% OMEs-diesel blend on a Euro-2 diesel passenger car engine. The 
results showed that PM emission decreases by up to $18 \%$ for the $10 \%$ OMEs-diesel blend, while the emissions from pure OMEs were reduced by $77 \%$. For pure OMEs an increase in $\mathrm{CO}, \mathrm{NO}_{\mathrm{x}}$ and formaldehyde (the formaldehyde pathway may prevent $\mathrm{C}_{2}$-formation, and thus soot precursors) emission was detected. Iannuzzi et al. [50] investigated the combustion behavior of pure OMEs, DMM and several blends of OMEs with diesel in a cylindrical constant volume chamber by optical diagnostics. Their results display a reduction in soot concentration during the soot formation dominated phase and an early start of oxidation. Consequently, they investigated emission performances of $5 \%$ and $10 \%$ OMEs-diesel blends [17] in a single cylinder heavy duty diesel engine. They observed a reduction in soot emissions compared to a commercial diesel close to $35 \%$ for the $10 \%$ OME-diesel blend and more than 10\% for the 5\% OME-diesel blend. It is not clear whether physical fuel properties (affecting evaporation and mixing) and/or chemical properties (controlling the temperature and kinetics of soot formation/combustion) are responsible for the different soot emissions using OME/diesel blends in internal combustion engines. For this purpose, combustion studies in a model burner are conducted in order to isolate the chemical from the physical effects.<smiles>COCC(C)OCC(C)OC(C)CO</smiles>

(a)<smiles>COCC(C)(C)OC</smiles>

(b)

Figure 1. Chemical structures of additives used: (a) tripropylene glycol methyl ether (TPGME), (b) polyoxymethylene dimethyl ethers (OMEs).

\subsection{Techniques Used for Soot Characterization}

Several ex situ and in situ techniques are employed for the chemical and physical characterization of soot. Ex situ techniques, such as electron microscopy, X-ray diffraction or gravimetric techniques [51,52] require sampling of the particles, which influences the combustion and thus soot formation process and in turn could alter the results. Therefore, for the investigation of soot formation during combustion, in situ techniques are preferred. Laser-based techniques have especially gained increasing attention as they permit temporally and spatially resolved visualization of soot during the formation and oxidation process. In the present study we employed laser-induced incandescence (LII) measurements for the investigation of the soot volume fraction produced by the different fuels, two-color pyrometry (2-CP) for flame temperature measurements and wide-angle light scattering (WALS) for the characterization of the aggregate size.

\subsubsection{Two-Color Pyrometry}

Two-color pyrometry is a widely used technique for measuring soot (and thus flame) temperatures. It has been applied to different kinds of flames and in engines [25,26,53-55]. This technique is based on the detection of the spectral radiance ratio at two wavelengths. The measured spectral intensity of radiation $E_{\mathrm{s} \lambda}$ emitted by soot at the temperature $T_{\mathrm{s}}$ at a certain wavelength $\lambda$ is dependent on the soot emissivity $\varepsilon_{\mathrm{s}}$ and can be described by Planck's law

$$
E_{\mathrm{s} \lambda}\left(\lambda, T_{\mathrm{s}}\right)=\tau(\lambda) \varepsilon_{\mathrm{s}}(\lambda) \frac{2 \pi h c^{2}}{\lambda^{5}\left(e^{h c / \lambda k T_{\mathrm{s}}}-1\right)},
$$

where $c$ is the speed of light, $h$ is Planck's constant, $k$ is the Boltzmann constant and $\tau(\lambda)$ is an optical parameter that accounts for the collection efficiency, solid angle, and detector sensitivity at the specific detection wavelength. The detection system can be calibrated for 
spectral sensitivity by measuring the radiation intensity emitted by a calibrated tungsten lamp in the same spectral range. The measured intensity of the calibrated lamp $E_{\mathrm{L} \lambda}$ then is

$$
E_{\mathrm{L} \lambda}(\lambda)=\tau(\lambda) M_{\mathrm{L}}(\lambda),
$$

where $M_{\mathrm{L}}(\lambda)$ is the known spectral intensity emitted by the lamp. From the ratio $E_{\mathrm{L} \lambda_{1}} / E_{\mathrm{L} \lambda_{2}}$ the relative sensitivity $\tau_{1 / 2}=\left(E_{\mathrm{L} \lambda 1} M_{\mathrm{L} \lambda 2}\right) /\left(E_{\mathrm{L} \lambda 2} M_{\mathrm{L} \lambda 1}\right)$ of the optical system can be computed. At this point soot temperature can be inferred in two different ways, i.e., applying the approximation of Wien's law [54] which would introduce some bias, or from the comparison between the experimental data (corrected according to the detection system sensitivity) and a spectral radiance ratio-temperature look-up table, which we chose in this work. We want to emphasize that $E_{\mathrm{S} \lambda}$ is the result of an integration process over the optical path, i.e., a line of sight measurement. In case of not rotationally symmetric flames without tomographic methods, the determined values of the temperature are only some kind of average along the line of sight. In contrast, for axially symmetric flames it is possible to obtain the radial distribution of soot radiation, e.g., through an Abel inversion procedure $[26,53]$.

\subsubsection{Laser-Induced Incandescence}

LII is based on the measurement of the enhanced thermal radiation emitted by (carbonaceous) particles after heating them up close to the sublimation temperature with a short laser pulse [23]. LII has been widely applied for the measurement of soot volume fraction in a variety of flames and for different fuel types [56-60]. For sufficiently high laser fluences, the prompt LII-signal is approximately proportional to the local soot volume fraction $f_{V}[23,61]$. For quantitative measurements, a calibration is necessary to bring the local LII-signal and volume fraction into relation. This calibration is usually done by performing laser extinction measurements on a reference flame [62]. Generally, LII signals are highly non-linear with laser fluence and the optimum fluence must be determined first.

\subsubsection{Wide-Angle Light Scattering}

By using LII it is possible to determine the soot volume fraction $f_{V}$ but no information about aggregate properties can be obtained by this method. Elastic light scattering (ELS) can be employed to determine the aggregate size, expressed as radius of gyration $R_{\mathrm{g}}$, and the aggregate morphology, described by the fractal dimension $D_{\mathrm{f}}$ [63]. The scattering intensity under various scattering angles $\theta$ depends on the size and morphology of the aggregates [63]. Measuring the scattering intensity $I$ under various scattering angles thus allows the evaluation of $R_{\mathrm{g}}$ in the so called Guinier regime and $D_{\mathrm{f}}$ in the power-law regime [63-65], where

$$
\begin{gathered}
\frac{I(0)}{I(q)} \approx 1+\frac{1}{3}\left(q R_{\mathrm{g}}\right)^{2}, \text { for } q R_{\mathrm{g}} \leq 1, \\
I(q) \approx C\left(q R_{\mathrm{g}}\right)^{-D_{\mathrm{f}}, \text { for } q R_{\mathrm{g}} \gg 1 .}
\end{gathered}
$$

Here $q=4 \pi / \lambda \cdot \sin (\theta / 2)$ is the magnitude of the scattering vector $\vec{q}$ for the incident wavelength $\lambda$ and $C$ is a constant of order unity. Generally, two kinds of experimental ELS set-up can be used. The first approach employs a scanning goniometer [64,66], which allows for a potentially high angular resolution, but comes with the drawback of a sequential and thus slow measurement procedure, restricting this method to stationary objects. The second approach uses multiple detectors [67-69] for simultaneous detection under several angles, yet, with the drawback of a limited number of detectors and, consequently, angular measurement positions. More recently, an approach called wide-angle light scattering (WALS) was introduced, which overcomes the limitations previously listed as it combines the advantages of a fast measurement and a high angular resolution [24]. Basically, an ellipsoidal mirror is used to image the scattered light over a wide range of angles and 
with a high angular resolution onto a planar detector. This technique has been applied to aerosols, laminar and turbulent premixed flames and for spray investigations [24,70-73].

\section{Experimental Apparatus}

\subsection{Combustion System}

The vaporization and combustion of the diesel blends were performed using a recently implemented diesel burner already presented and described in our previous work [74]. Since the burner system has been illustrated before, only a brief description is given here. The combustion is prepared by a two-step procedure. First, the pre-vaporization of the fuel: this is carried out in the first section of the burner, the vaporization zone. This zone contains the diesel inlet which is connected to the fuel tank and the gear pump (HNPM $\left.\mathrm{mzr}^{\circledR}-2921\right)$. Second, a mixture of the already vaporized fuel $(0.175 \mathrm{~L} / \mathrm{min}$ gas volume flow at $380{ }^{\circ} \mathrm{C}$, corresponding to $\left.0.45 \mathrm{~g} / \mathrm{min}\right)$ with $\mathrm{N}_{2}\left(0.3 \mathrm{~L} / \mathrm{min}\right.$, pre-heated up to $\left.380^{\circ} \mathrm{C}\right)$ is prepared. Nitrogen is chosen as carrier gas instead of air to avoid self-ignition of the diesel (occurring at $210^{\circ} \mathrm{C}$ ). At the position of insertion, $\mathrm{N}_{2}$ is forced into a swirling flow that facilitates the efficient blending of the fuel and the carrier gas. The vaporization and mixing sections are heated up and kept at $380{ }^{\circ} \mathrm{C}$. The inner flow temperature is controlled by two thermocouples. The fuel- $\mathrm{N}_{2}$ mixture and the flow homogenization are achieved by the large diameter of the burner inlet tube $(45 \mathrm{~mm})$ and a combination of a porous set and a flow homogenizer positioned at the end of the mixing section just before the outlet. Finally, we introduced a conical nozzle, with an inner diameter of $2.5 \mathrm{~mm}$, for stabilization of the flame. The flame is further stabilized by air $(18 \mathrm{~L} / \mathrm{min}$ flow rate (standard temperature and pressure), pre-heated to $380^{\circ} \mathrm{C}$ ) streaming through a co-flow cylinder filled with glass pearls with a diameter of $3 \mathrm{~mm}$ that surrounds the nozzle. The combustion system implemented generates a laminar diffusion flame. The flame is about $95 \mathrm{~mm}$ long and $8 \mathrm{~mm}$ wide, while its Reynolds number is $\sim 100$. Measurements were carried out on flames from different fuel-additive mixtures. In the following, the pure diesel fuel is referred to as baseline. As additives blended with the baseline fuel, TPGME, $\mathrm{OME}_{2}$ and $\mathrm{OME}_{3-5}$ were each used in concentrations listed in Table 1. In the literature, see e.g., Iannuzi et al. [17] and references therein, a wide range of additive concentrations has been used. The concentrations used in this work both cover small concentrations which may be realistic for practical use as additive, namely $1 \%$ and potentially $3 \%$, and also a larger admixture of $9 \%$ to check if a further increase significantly alters the results. As discussed below, in the case of TPGME a concentration of $9 \%$ was necessary to obtain significant effects of the additive on soot emission.

Table 1. Additives and volume concentrations of additives used for all investigations. All additives were mixed with baseline fuel.

\begin{tabular}{cc}
\hline Additive Name & Additive Volume Concentration under Investigation \\
\hline TPGME & $1 \%, 3 \%, 9 \%$ \\
$\mathrm{OME}_{2}$ & $1 \%, 3 \%, 9 \%$ \\
$\mathrm{OME}_{3-5}$ & $1 \%, 3 \%, 9 \%$ \\
\hline
\end{tabular}

\subsection{Two-Color Pyrometry Set-Up}

In the two-color pyrometry experiments, two flame images are collected simultaneously on a CCD chip at two selected wavelengths. The set-up employed consists of an intensified CCD camera (Andor, iStar sCMOS18F63, 16 bit) with a resolution of $1024 \times 1024$ pixels $(2 \mu$ s gate width, $8 \mathrm{~Hz}$ repetition rate) and an image doubler (LaVision $\mathrm{GmbH}$ ). The image doubler is a stereoscope providing an image pair on a single camera chip at the cost of spatial resolution. Two band-pass filters at $600 \mathrm{~nm}$ and $750 \mathrm{~nm}$ central wavelength, with $50 \mathrm{~nm}$ FWHM each, are mounted in front of the image doubler. We selected these two wavelengths in the red region of the visible spectra because the soot emission intensity is higher compared to smaller wavelengths and, at the same time, the 
camera employed has a good sensitivity in this region. The detection system was calibrated by a tungsten calibration lamp (Ocean Optics, model HL-3-CAL).

\subsection{Laser-Induced Incandescence Set-Up}

The LII set-up, shown in Figure 2, is constituted by a Q-switched pulsed Nd:YAG laser (Quantel, Q-smart 850), with a repetition rate of $10 \mathrm{~Hz}$ and a pulse width of $5 \mathrm{~ns}$, and a set of optics for laser energy modulation and beam shaping. The laser wavelength is $1064 \mathrm{~nm}$, which allows the excitation and detection of the incandescence signal, without exciting laser-induced fluorescence (LIF) signals from polycyclic aromatic hydrocarbons. The laser beam has a diameter of $6 \mathrm{~mm}$ at the output. The first set of optics' area half-wave plate and a thin film polarizer that permit the regulation of the fluence. By positioning the half-wave plate directly in front of the thin film polarizer it is possible to adjust the laser energy through small rotations of the half-wave plate. After the thin film polarizer, two cylindrical lenses, $f_{1}=-50 \mathrm{~mm}$ and $f_{2}=200 \mathrm{~mm}$, are inserted for vertical expansion of the beam. In this way, a laser sheet is created. A third lens, $f_{3}=1000 \mathrm{~mm}$, is employed to narrow the width of the laser sheet horizontally until it reaches the focus, which corresponds to the measurement area in the flame. The thickness of the sheet in the focal point is $0.6 \mathrm{~mm}$. The laser sheet edges, usually not sharp, are removed by an aperture placed before the flame, which leads to a final sheet height of $30 \mathrm{~mm}$ with sharp edges. A further inspection of the laser sheet profile by a beam profiling camera (OPHIR Photonics, SP620U Spiricon) confirmed the uniformity of the laser sheet as shown in Figure 3.

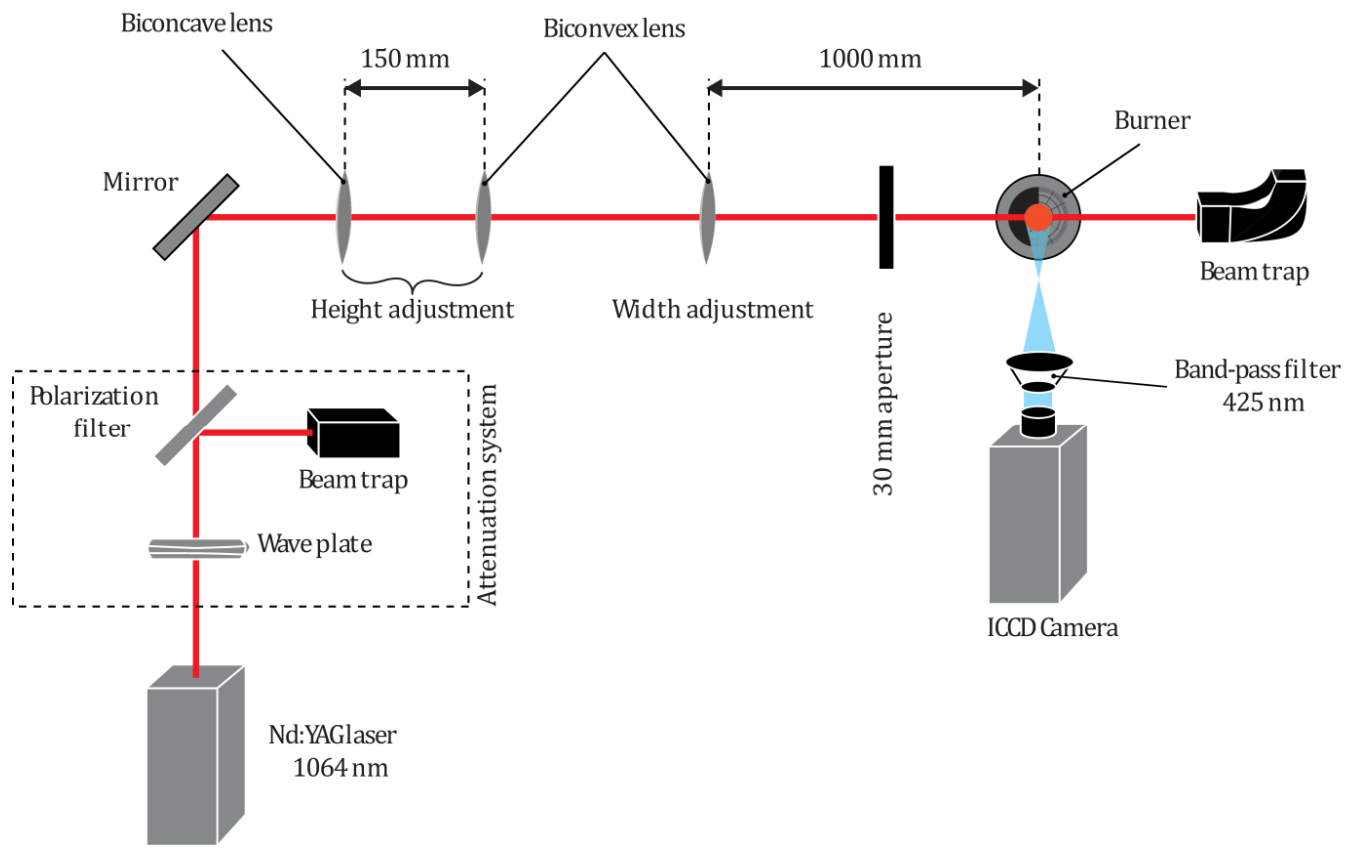

Figure 2. LII set-up used for comparative measurements. Red lines depict the path of the laser beam.

For the measurements we utilized a fluence of $0.15 \mathrm{~J} / \mathrm{cm}^{2}$, selected after optimization of the fluence in relation to the LII signal intensity (see [74]). The 2D-LII images were collected through an intensified CCD camera (Andor, iStarDH334T-18F-E3, 16 bit). The intensifier gate width was set to $20 \mathrm{~ns}$, the repetition rate to $10 \mathrm{~Hz}$ and the pixel resolution set was $354 \times 301$ pixels. In front of the objective lens of the camera a band-pass filter (center wavelength $425 \mathrm{~nm}, 50 \mathrm{~nm}$ FWHM) is placed to detect mainly the LII signal and reduce the natural flame luminosity (mostly in the red shifted part of the spectrum with respect to the filter). Quantitative measurements are only possible after calibration of the LII signal. The calibration was performed by extinction measurements following the procedure already described by Palazzo et al. [74]. The calibration requires the knowledge of the absorption function $E(m)$, that takes into account the index of refraction of soot. This value is still 
debated within the scientific community; nevertheless, a common value usually employed for $1064 \mathrm{~nm}$ wavelength is 0.3 [75-77], which we used also here. Although the real value of $E(m)$ can vary by varying the combustion conditions (e.g., fuel and burner), this change only slightly affects the relative comparison between the different fuels since the soot formation conditions in the diesel burner are the same and the values of soot volume fraction obtained are always compared to the baseline diesel. Finally, it should be considered that beam extinction is not only due to absorption but also to scattering. We estimated by WALS measurements that the aggregate size of the particles was between $150 \mathrm{~nm}$ and $200 \mathrm{~nm}$, leading to a share of about $20-25 \%$ of scattering on the overall attenuation [63]. The extinction coefficient was corrected accordingly.

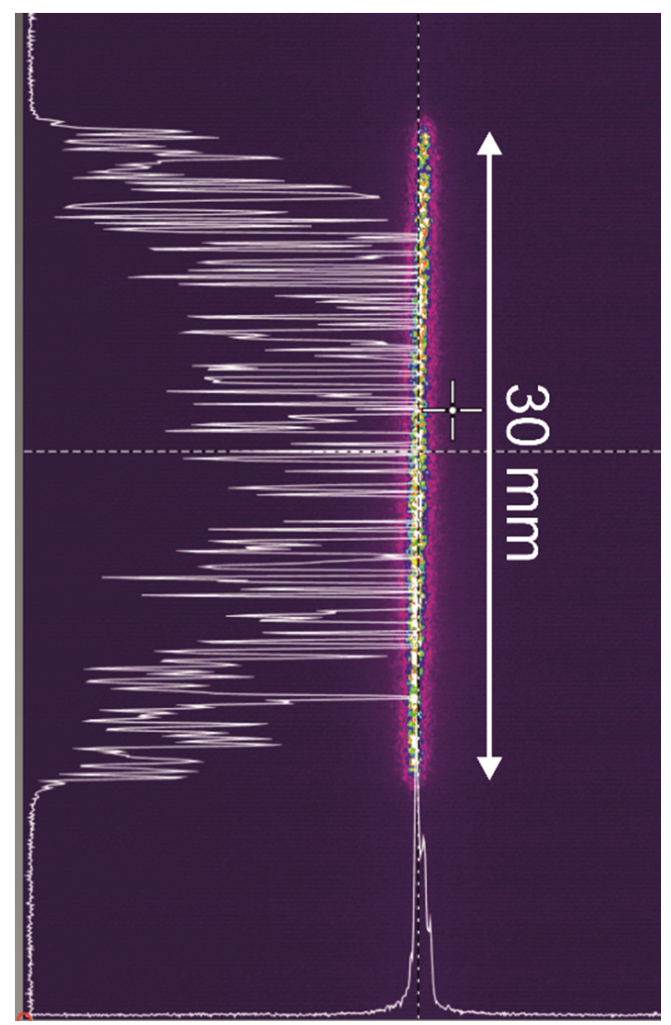

Figure 3. Beam profile of the laser sheet ( $30 \mathrm{~mm}$ high, $0.6 \mathrm{~mm}$ thick) used for laser-induced incandescence (LII) measurement.

\subsection{Wide-Angle Light Scattering Set-up}

Figure 4 displays the WALS set-up employed for aggregate size measurements. This set-up has been used before [76]. The principal component of the WALS set-up is the ellipsoidal mirror. The mirror has two focal points with $\Delta f=600 \mathrm{~mm}$. The light beam from a cw-laser (Qioptiq, Nano-532-250) with $532 \mathrm{~nm}$ wavelength, after being vertically polarized by a Glan-Taylor prism, is guided by the optics to pass through the central axis of the mirror (on this purpose two slits of $10 \mathrm{~mm}$ have been cut on the opposite sides of the mirror body). In this way the beam intersects the flame, which is placed within the mirror. The laser beam is by an $f=300 \mathrm{~mm}$ lens focused into the measurement volume that corresponds to the first focal point of the ellipsoidal mirror. In the second focal point of the mirror, where the scattered light from soot aggregates is focused, the aperture of a CCD-camera (AVT, PIKE F-100B, $1000 \times 1000$ pixels, 16 bit) is arranged preceded by a bandpass filter ( $535 \mathrm{~nm}$ wavelength). The filter is employed to limit the entrance of ambient light and flame luminosity. For the measurements we utilized a laser power of $35 \mathrm{~mW}$ ( $200 \mathrm{~mW}$ is the maximum power, which was used for the calibration with nitrogen) and a camera exposure time of $43 \mu \mathrm{s}$ ( $3 \mathrm{~s}$ was set for the calibration). Before carrying out the measurements, the calibration of the optical set-up was performed following the procedure 
used before [76]. Accordingly, 20 WALS-images of nitrogen were acquired and averaged to obtain a calibration image. When irradiated with vertically polarized light, nitrogen gas molecules in the Rayleigh regime scatter in an isotropic way in the scattering plane, i.e., with a scattering intensity identical in every direction. The calibration image obtained displays a $1 / \sin (\Theta)$ scattering intensity distribution over the angle, accounting for the angular dependence of the size of the measurement volume.

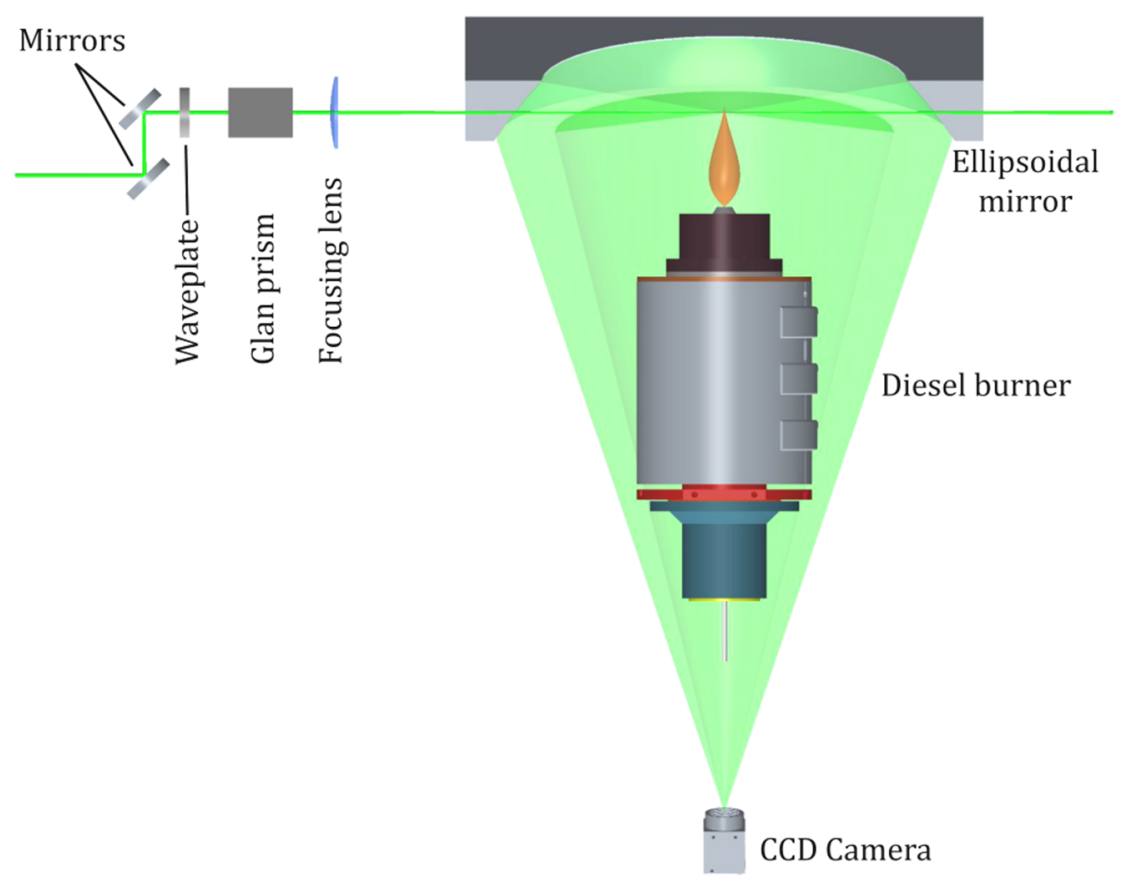

Figure 4. Wide-angle light scattering (WALS) set-up. Green lines depict the path of the laser beam while the green cone represents the scattered light collected by the mirror and imaged into the CCD camera.

\section{Results and Discussion}

We characterized the soot properties in the annular region of the flame, where soot is mainly concentrated, in heights above the burner outlet (HAB) from $20 \mathrm{~mm}$ to $90 \mathrm{~mm}$ in steps of $10 \mathrm{~mm}$. Figure 5 represents a soot luminosity image of the flame, precisely an average of 200 single shot images collected with the $750 \mathrm{~nm}$ band-pass filter, $50 \mathrm{~nm}$ FWHM, (baseline diesel, images acquired at the setting condition stated in Section 3.2). The radial profile of the diffusion flame from $10 \mathrm{~mm}$ to $70 \mathrm{~mm}$ HAB exhibits two zones where the concentration of soot is higher, both located symmetrically in the annular region, while in the central region of the flame the soot volume fraction significantly decreases. This behavior is in agreement with the literature [78] and can be explained by the diffusion of air-and thus oxygen - from the outside. This creates a stoichiometric region for combustion; right inside this stoichiometric region a fuel-rich area occurs where soot is formed. Above $70 \mathrm{~mm} \mathrm{HAB}$ the soot region spreads horizontally and also covers the center of the flame. Additionally, the regions in which the 2D-LII signals and two-color pyrometry data were evaluated for further processing are marked as red regions in Figure 5. The red regions correspond to a $2 \mathrm{~mm} \times 2.4 \mathrm{~mm}$ area (20 pixels $\times 24$ pixels). The grey dots represent the positions of the point-wise WALS measurements. Regarding the results obtained from each measurement technique, we want to emphasize that besides variations in the respective parameters of the optical diagnostics (e.g., $5 \%$ laser fluence fluctuations for LII) the precision of the results is mainly governed by slight fluctuations in the flame. Here, variations in the flow rates ( $1 \%$ for the diesel flow rate, $0.5 \%$ for the gas flow rates) play a certain role as well as residual movements of the flame which are difficult to quantify. Nonetheless, the overall precision of the measurements is reflected by the standard deviations of the data for the various techniques. 


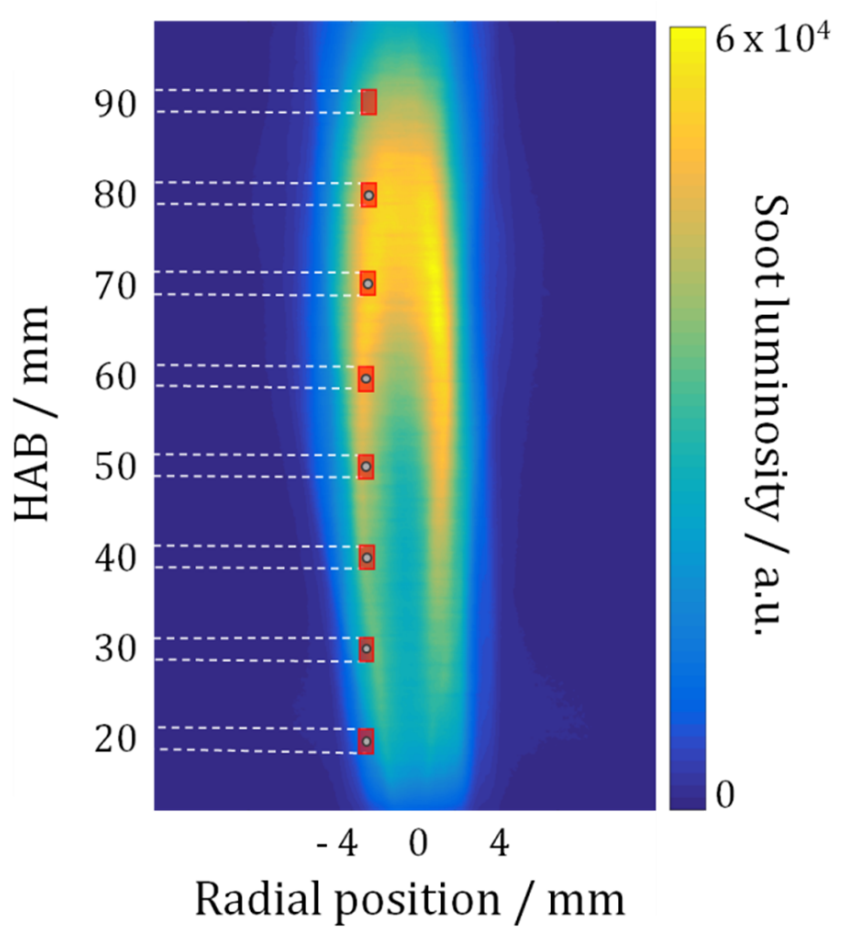

Figure 5. False color soot luminosity image of the laminar diffusion flame. The areas considered for further detailed LII and two-color pyrometry evaluation are highlighted with red rectangles while the grey dots represent the WALS measurement points.

\subsection{Impact of Additives on Soot Temperature}

The soot temperature profiles, obtained from the ratio of the soot radiance at two different wavelengths, are shown in Figure 6. The data-points shown are the average temperatures determined in the area considered for evaluation (see Figure 5.) after superimposing the two flame images collected simultaneously at $600 \mathrm{~nm}$ and $750 \mathrm{~nm}$. For every fuel, 200 couples of images $(600 \mathrm{~nm} / 750 \mathrm{~nm})$ were recorded. We evaluated the flame temperature for every image-couple which led to 200 temperature profiles which were averaged in turn. In general, the soot particle temperature increases slightly within the first centimeters above the burner outlet, then levels off and finally decreases slightly at higher HABs. Similar soot temperature trends have been observed in the literature for diffusion flames [26]. Generally, the temperatures obtained at atmospheric conditions are lower than those measured for in-cylinder flames that typically range between $2200 \mathrm{~K}$ and $2700 \mathrm{~K}$ [79]. Furthermore, in this work the co-flow used to shield the flame and the nitrogen dilution could cool the flame slightly. The additives inserted in the baseline fuel appear to have only a small effect on flame temperature. In the case of the $3 \% \mathrm{OME}_{3-5}$-diesel blend and the 3\% TPGME-diesel blend the flames are, on average, about $40 \mathrm{~K}$ to $45 \mathrm{~K}$ cooler compared to the baseline. The maximum temperature difference of up to $70 \mathrm{~K}$ between the above-mentioned blends and the baseline is reached at $50 \mathrm{~mm}$ and $60 \mathrm{~mm} \mathrm{HAB}$. The errors calculated from the standard deviation of the 200 images vary between $20 \mathrm{~K}$ and $40 \mathrm{~K}$ (mainly due to the flame flickering). 


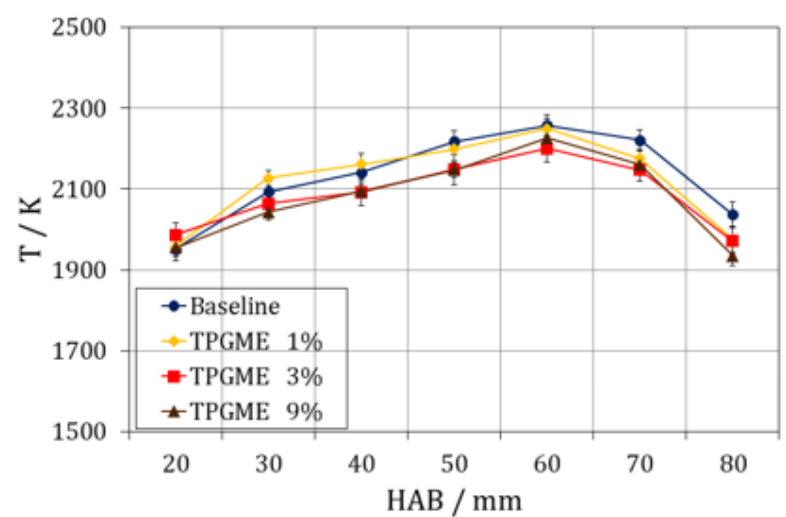

(a)

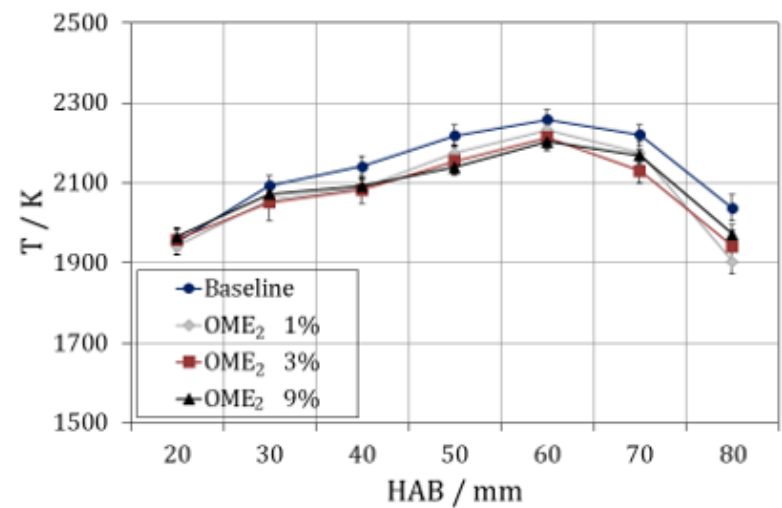

(b)

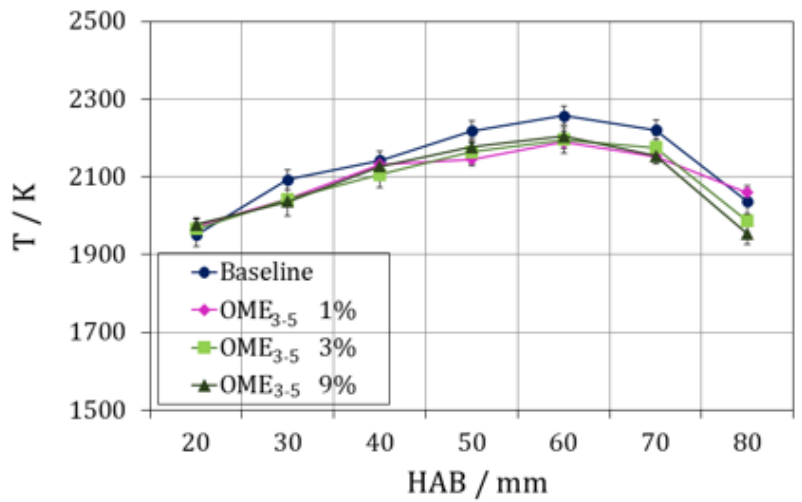

(c)

Figure 6. Vertical temperature trends for baseline and (a) TPGME-diesel blends (1\% vol, 3\%vol and $9 \%$ vol), (b) $\mathrm{OME}_{2}$-diesel blends (1\% vol, 3\% vol and 9\% vol) and (c) $\mathrm{OME}_{3-5}-$ diesel (1\% vol, 3\% vol and $9 \% \mathrm{vol})$. Error bars represent standard deviation of approx. 200 single-shot results.

\subsection{Impact of Additives on Soot Volume Fraction}

We acquired 5000 single-shot LII images of the flame for every fuel and blend under study. Due to small fluctuations of the flame [74], it was not possible to evaluate all images, therefore a selection based on a symmetry criterion was applied. For this purpose, a Matlab $^{\circledR}$ (R2016a, The MathWorks, Inc., Natick, MA, USA) filter was implemented. The filter scans the images for the central part of the flame (the dark region with low soot concentration between the two layers with high soot concentration) and calculates the width of this region; if the width of this area is between $6 \mathrm{~mm}$ and $8 \mathrm{~mm}$ (the width of the flame) for the entire height, the images pass the filter, otherwise they are rejected. 
The selection led to single out around 1000 LII images for every fuel. From the images selected, an averaged image was obtained and subsequently used for soot quantification. The average of 20 single-shot images with the laser turned off constituted the background image (accounting for flame luminosity, ambient light and dark counts of the camera), which was subtracted from the average LII-image. At every HAB, the averaged $f_{V}$ value within the measurement area (the red areas in Figure 5) was determined and used for comparison with the other fuels. The LII set-up was calibrated for absolute $f_{V}$ by extinction measurements as in our previous work [74]. Figure 7 displays the vertical trends of $f_{V}$ evaluated from LII measurements of TPGME-diesel blends, $\mathrm{OME}_{2}-$ and $\mathrm{OME}_{3-5}$-diesel blends. The soot volume fractions of the additive-diesel blends are compared with $f_{V}$ values of the baseline diesel, acquired at the same conditions. The error bars are calculated from the standard deviation of the $1000 \mathrm{LII}$ images used to obtain the averaged image at the respective position. The trends clearly show an increase in the soot volume fraction with increasing $\mathrm{HAB}$ until $70 \mathrm{~mm}$ followed by a strong decrease. Soot particles form and grow in the first section of the flame, i.e., from 10-70 mm HAB. Consequently, we detect an increase in soot volume fraction. Although oxidation processes are always present from the beginning of combustion, they become predominant above $70 \mathrm{~mm} \mathrm{HAB}$, leading to a drop in the soot volume fraction.

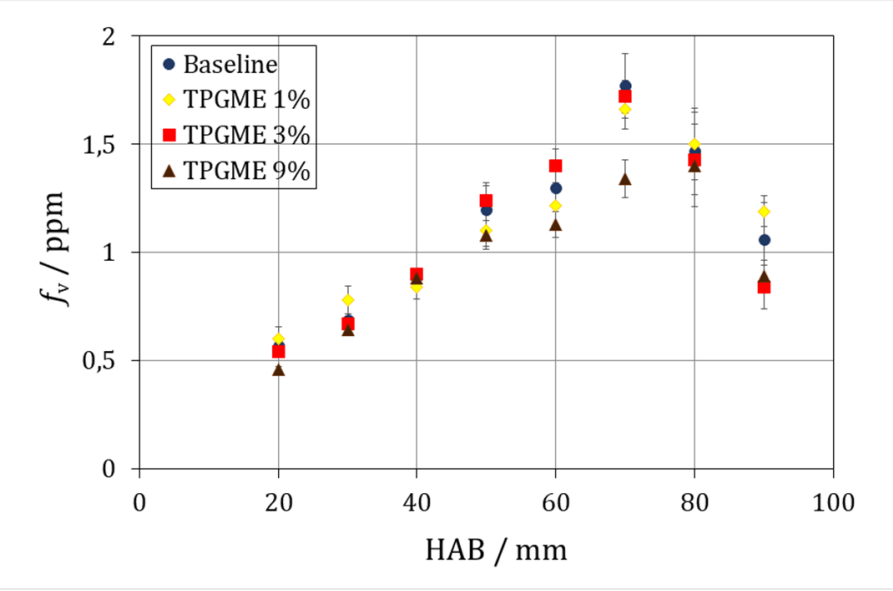

(a)

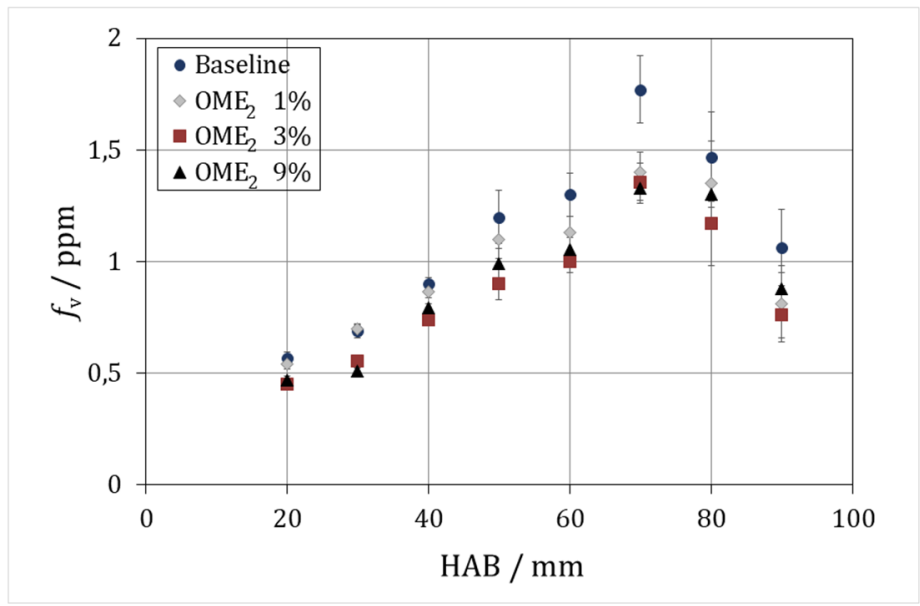

(b)

Figure 7. Cont. 


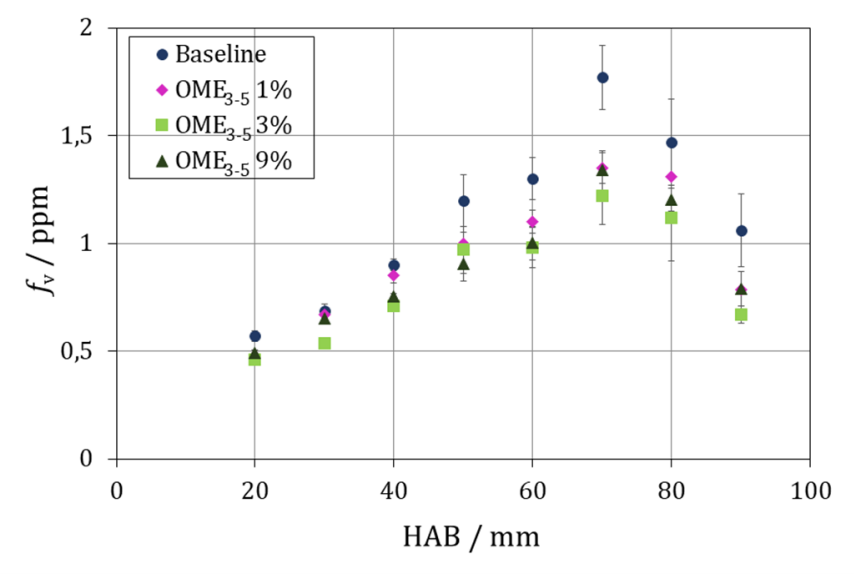

(c)

Figure 7. Vertical $f_{V}$ trends for (a) Baseline and TPGME-diesel blends (1\% vol, 3\%vol and 9\% vol) (b) baseline and $\mathrm{OME}_{2}$-diesel blends ( $1 \%$ vol, $3 \% \mathrm{vol}$ and $9 \%$ vol) and (c) baseline and $\mathrm{OME}_{3-5}-$ diesel blends ( $1 \% \mathrm{vol}, 3 \% \mathrm{vol}$ and $9 \% \mathrm{vol})$. Error bars represent standard deviation of approx. 1000 singleshot results.

Focusing on the comparison of the additized diesels with the baseline diesel, we can conclude:

1. TPGME only affects soot production in a minor way, with the exception of the $9 \%$ TPGME-blend at $70 \mathrm{~mm}$ HAB and 3\% TPGME-blend at $90 \mathrm{~mm}$ HAB.

2. Both other additives, $\mathrm{OME}_{2}$ and $\mathrm{OME}_{3-5}$, cause a reduction in $f_{V}$ : a slight one for $\mathrm{OME}_{2}$ and significant one for $\mathrm{OME}_{3-5}$, especially higher in the flame.

3. The additive concentration, especially for OMEs, plays an important role. Although the $1 \%$ blend already slightly diminishes soot emissions, the 3\% and 9\% OME-diesel blends are more effective compared to the $1 \%$ blend.

In order to better quantify the impact of the additive-diesel blends, we calculated the soot reduction in the additized diesel with respect to the $f_{V}$ determined for the baseline diesel. The results, grouped by the additive volume percentage in the diesel, are shown in Figure 8. Considering the 1\% additive-diesel blends, Figure $8 \mathrm{a}$, one can see on the one hand that the OME additives reduce soot for all HABs, except for $\mathrm{OME}_{2}$ at $30 \mathrm{~mm} \mathrm{HAB}$; on the other hand, the soot volume fraction for TPGME shows an opposing trend, i.e., it provokes an increase in $f_{V}$ at $20 \mathrm{~mm}, 30 \mathrm{~mm}, 80 \mathrm{~mm}$ and $90 \mathrm{~mm} \mathrm{HAB}$, and a soot decrease at the other heights. However, it should be taken into account that the measurement errors (see Figure 7) are about $7 \%$ in the lower part of the flame and $11 \%$ in the upper part of the flame (due to higher flame fluctuations), implicating the differences between additized diesel and pure baseline diesel within a few percentage points are not significant. A clear effect thus cannot be seen in the case of the 1\% TPGME-diesel blend. In contrast, the insertion of only $1 \%$ of $\mathrm{OME}_{2}$ and $\mathrm{OME}_{3-5}$ into the baseline fuel causes a soot reduction by between $15 \%$ and $25 \%$, and this reduction is especially pronounced in the upper part of the flame. Increasing the concentration of the additives to $3 \%$ vol, Figure $8 b$, the tendency of OMEs to decrease the soot yield is more evident, in particular at $90 \mathrm{~mm}$ HAB where $\mathrm{OME}_{3-5}$ is capable of suppressing soot production up to $36 \%$. In $3 \%$ concentration, TPGME only shows a significant reduction effect at $90 \mathrm{~mm} \mathrm{HAB}$, where the soot yield is reduced by $20 \%$ compared to the baseline. Finally, for $9 \%$ vol of additives, Figure 8 c, basically every additive studied is able to reduce soot emissions; again, the effect is more accentuated in the upper part of the flame. The effect of TPGME in this case is comparable to that of the OMEs, i.e., the decrease in soot volume fraction at $70 \mathrm{~mm} \mathrm{HAB}$ is about $22 \%$ for TPGME to $23 \%$ for $\mathrm{OME}_{3-5}$. To sum up, $\mathrm{OME}_{3-5}$ is the most effective additive in reducing the amount of soot emitted by the diffusion flame under study when compared with $\mathrm{OME}_{2}$ and TPGME. 
$\mathrm{OME}_{3-5}$ is the additive with more $\mathrm{CH}_{2}-\mathrm{O}$ groups and thus more oxygen content, which can explain the better performance of this compound. Two outcomes should be given special consideration:

1. On average the additive's effect is always more pronounced in the upper part of the flame. Consequently, the additives most probably enhance the oxidation of soot (that is higher in the upper part of the flame). Nevertheless, more investigations that should also involve soot precursor measurements are required to verify the soot formation and oxidation mechanism.

2. The soot reduction effect of TPGME increases by increasing the additive's concentration. Yet, this is not valid for the OMEs. The best result for $\mathrm{OME}_{2}$ and $\mathrm{OME}_{3-5}$ is achieved at the concentration of $3 \%$, not at $9 \%$ as expected. The non-linear correlation between the OME soot reducing effect and its concentration has already been observed in other studies [80-83]. Song et al. and Kocis et al. reported that $2 \%$ and $4 \%$ $\mathrm{OME}_{1}$-diesel blends decreased soot by $46 \%$ and $57 \%$, respectively [82,83]. Under the same conditions, tests performed with a $30 \%$ blend of $\mathrm{OME}_{1}$ in diesel showed less PM reduction (only about $35 \%$ ) $[80,81]$. In essence, the addition of OMEs with a concentration of few percent seems promising for practical application, while the requirement of a significant admixture of TPGME to obtain relevant soot reduction is rather a hindrance for technical use.

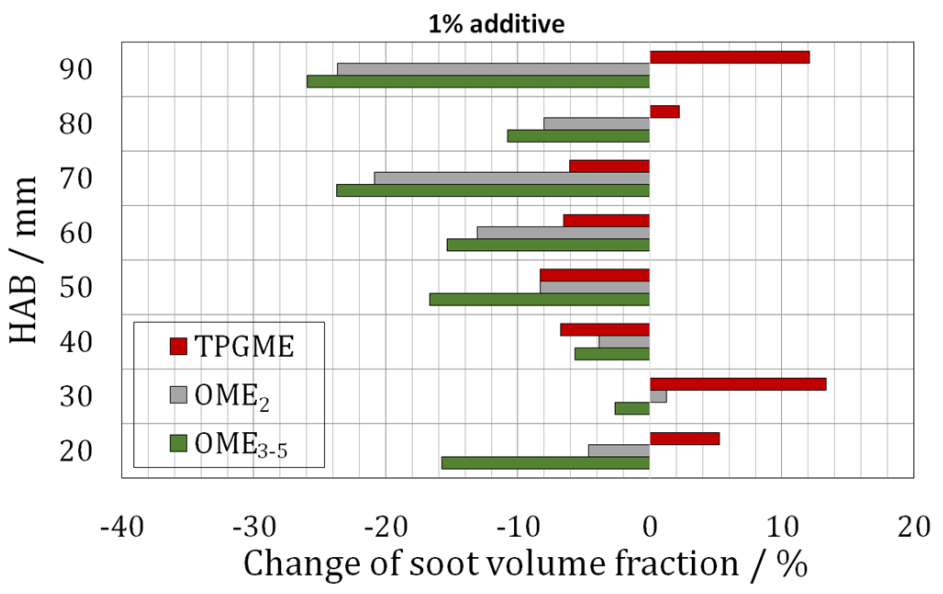

(a)

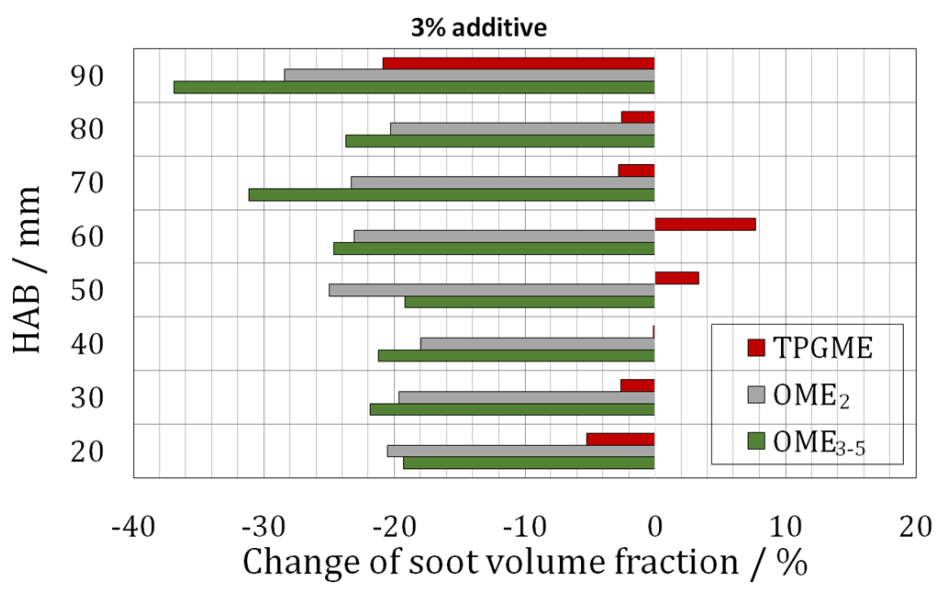

(b)

Figure 8. Cont. 


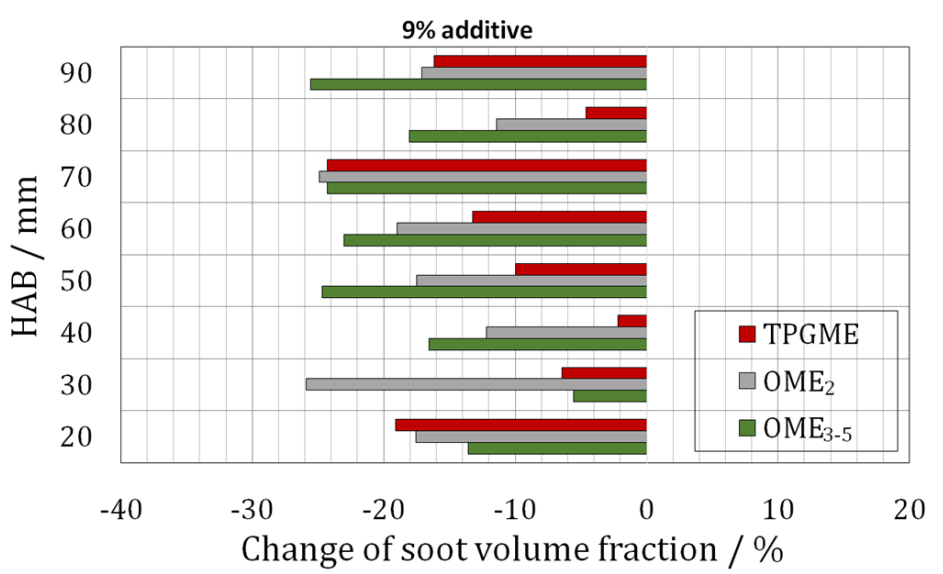

(c)

Figure 8. Comparison of $f_{V}$ change between TPGME, $\mathrm{OME}_{2}$ and $\mathrm{OME}_{3-5}$ diesel blends with respect to the baseline with (a) $1 \%$ of additives, (b) $3 \%$ of additives and (c) $9 \%$ of additives.

\subsection{Impact of Additives on Soot Aggregate Size}

WALS measurements were carried out from $20 \mathrm{~mm}$ to $80 \mathrm{~mm}$ HAB in the flame's annular region. The measurement point at $90 \mathrm{~mm}$ HAB was not considered since the homogeneous flame-properties within the measurement volume required for WALS were not fulfilled at this height due to flame fluctuations. We acquired 5000 scattering images for every measurement point that were processed to scattering data with an angular resolution of $1^{\circ}$ [24]. The scattering data from fractal aggregates should, after calibration, decay monotonously with increasing scattering angle [63]. As forward scattering predominantly influences the $R_{\mathrm{g}}$-evaluation in the Guinier regime, scattering data with continuous positive slope (more than five consecutive data points where the scattering intensity rises by increasing the angle) between $10^{\circ}$ and $90^{\circ}$ were discarded by a filter previously described [74]. For the backward scattering, between $90^{\circ}$ and $170^{\circ}$, a larger number (up to ten) of data points with increasing intensity were permitted by the filter. From the 5000 single-images acquired, about 200 images passed the filter and were evaluated in the Guinier regime. The effective soot aggregate size $R_{\mathrm{g}, \text { eff }}$ can be calculated from the measured scattering data $I(q)$ using [71]

$$
\frac{1}{I(q)}=\frac{1}{I(0)}+q^{2} \frac{R_{\mathrm{g}, \text { eff }}^{2}}{3 I(0)} .
$$

By linearly fitting $1 / I(q)$ against $q^{2}$ within the limit $I(q) / I(0) \leq 2$ for the Guinier regime [63], $I(q=0)$ and the slope $m=R_{g, e f f}^{2} / 3 I(0)$ are obtained and consequently the effective radius of gyration $R_{\mathrm{g}, \text { eff }}$ can be determined. The distribution of the effective radii of gyration was used to calculate the median value, $\mu_{\mathrm{g} \text {,eff, }}$ taking into account that the statistical distribution of the radii of gyration exhibits a lognormal shape, which is in agreement with previous work $[72,74]$. One should keep in mind that with every single-shot image a whole aggregate ensemble is measured. These ensembles usually also exhibit a broad size distribution showing a lognormal shape with a median and a geometric standard deviation [70]. However, in this work we measure effective radii of gyration and determine their distribution parameters, not to be confused with the aggregate size distribution parameters. The $\mu_{\mathrm{g} \text {,eff }}$ obtained was used for the comparison of soot aggregate sizes between additized and pure diesel and is shown in Figure 9. As expected, the size of the aggregates increases with increasing $\mathrm{HAB}$ for all fuels; the trend illustrated is explained by the increasing aggregation time for higher HABs which leads to larger aggregates at the flame tip. Focusing on the effect of the different additives on aggregate sizes, it is observable that OMEs have a higher positive impact, i.e., the aggregates are smaller compared to TPGME-diesel blends. Moreover, TPGME decreases the size of the soot aggregates emitted only when it is inserted in the concentration of $9 \%$, while in lower concentration there is no significant difference. 
On the contrary, the aggregates formed by $1 \%, 3 \%$ and $9 \%$ of $\mathrm{OME}_{2}-$ and $\mathrm{OME}_{3-5}-$ diesel blends appear to be slightly smaller compared to the baseline's particles between $60 \mathrm{~mm}$ and $80 \mathrm{~mm} \mathrm{HAB}$.

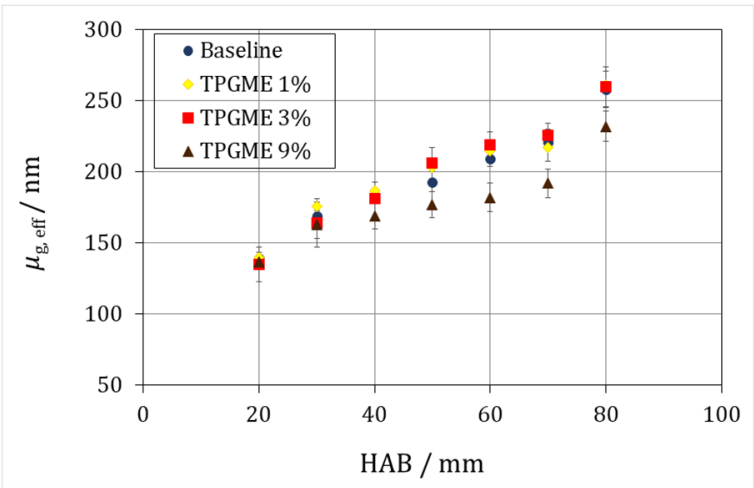

(a)

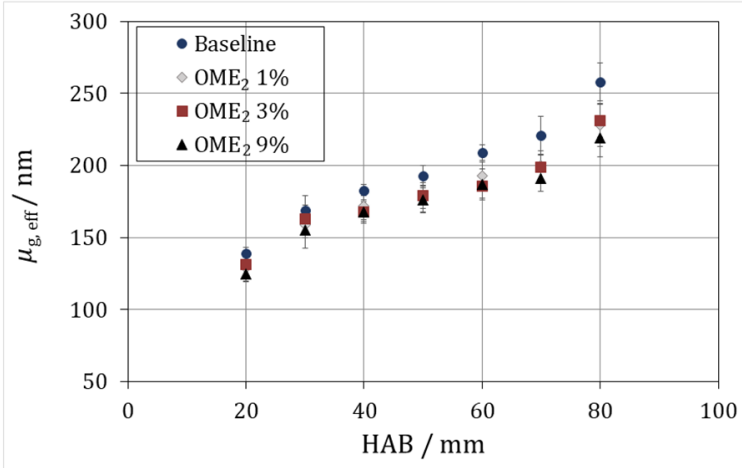

(b)

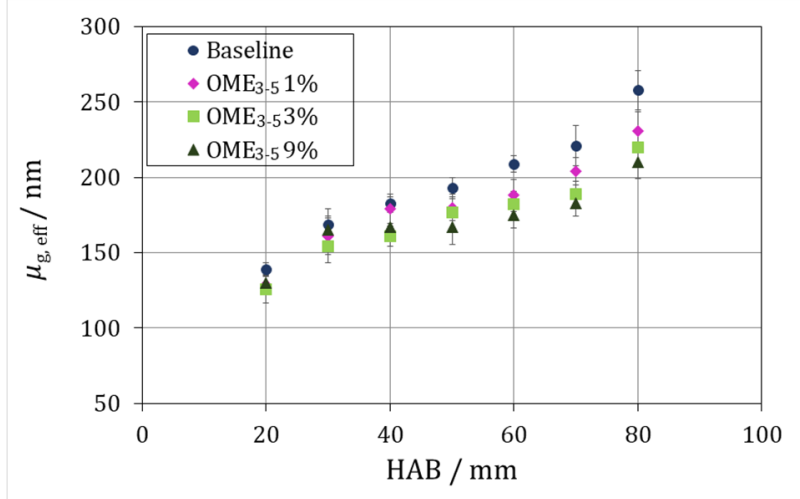

(c)

Figure 9. Vertical $\mu_{\mathrm{g} \text {,eff }}$ trends for baseline and (a) TPGME-diesel blends (1\% vol, 3\% vol and 9\% vol), (b) $\mathrm{OME}_{2}$-diesel blends (1\% vol, 3\%vol and 9\% vol) and (c) $\mathrm{OME}_{3-5}$-diesel blends (1\% vol, 3\% vol and $9 \% \mathrm{vol})$. Error bars represent standard deviation of approx. 200 single-shot results.

In this case we also calculated the relative changes of the effective median aggregates size for the additized diesel with respect to the baseline. The results are shown in Figure 10. TPGME, when inserted with $1 \%$ and $3 \%$ vol, seems to increase the size of the particles up to $6.5 \%$ at certain heights. Nevertheless, the error bars calculated from the geometric standard deviation of the $R_{\mathrm{g}, \text { eff }}$ distribution range between $5 \%$ and $10 \%$. Therefore, the increase in the aggregate size cannot be considered as significant since the difference 
between the additized diesel and the baseline are contained within the $1 \sigma$-intervals. As for $\mathrm{OME}_{2}$ and $\mathrm{OME}_{3-5}$, they cause a reduction in median aggregate size at every HAB and their effect increases with increasing additive concentration. Moreover, in agreement with the results of the LII measurements, the influence of the OMEs on the aggregate size is pronounced between $60 \mathrm{~mm}$ and $80 \mathrm{~mm}$ HAB. Taking the fractal relationship into account and assuming a fractal dimension of 1.8 [63], the reduction in aggregate mass roughly follows the reduction in soot volume fraction; for instance, the insertion of $3 \%$ of $\mathrm{OME}_{3-5}$, the additive with the largest impact on aggregate size, causes a decrease in $\mu_{\mathrm{g} \text {,eff }}$ of about $15 \%$ (at $60 \mathrm{~mm} \mathrm{HAB}$ ) compared to the baseline diesel. Assuming constant primary particle sizes, this corresponds to a reduction in the aggregate mass of about $25 \%$, comparable to the reduction in soot volume fraction under these conditions.

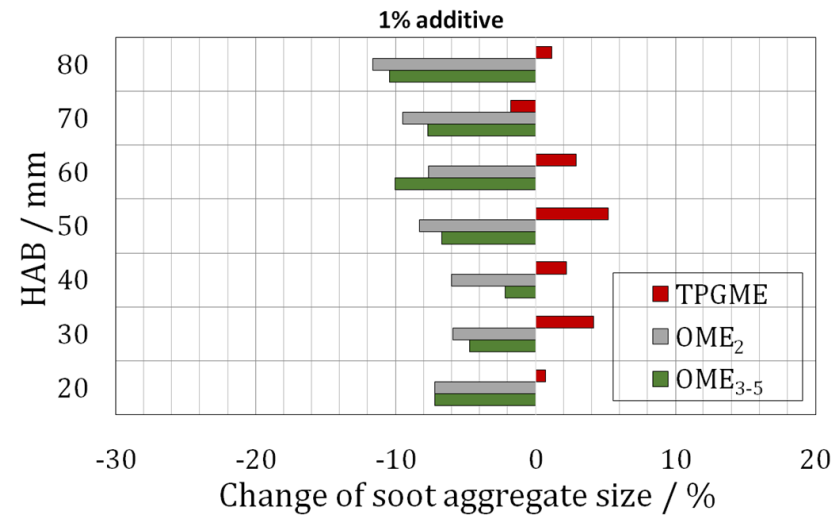

(a)

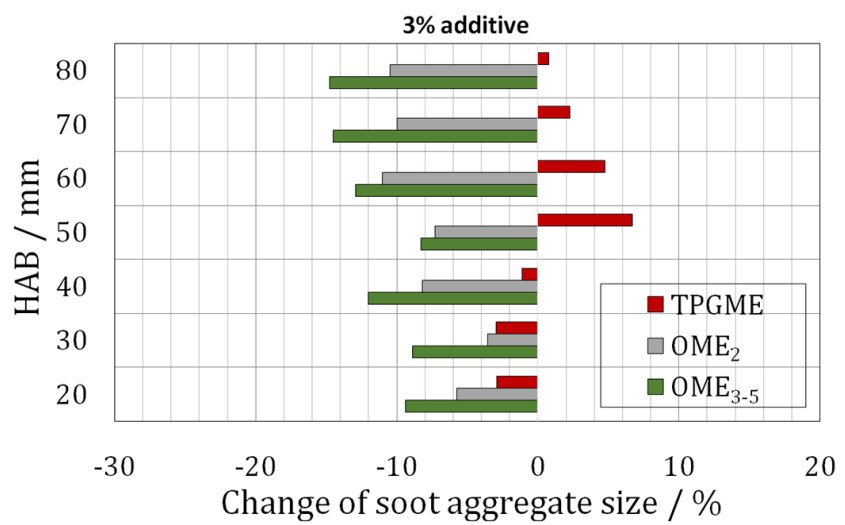

(b)

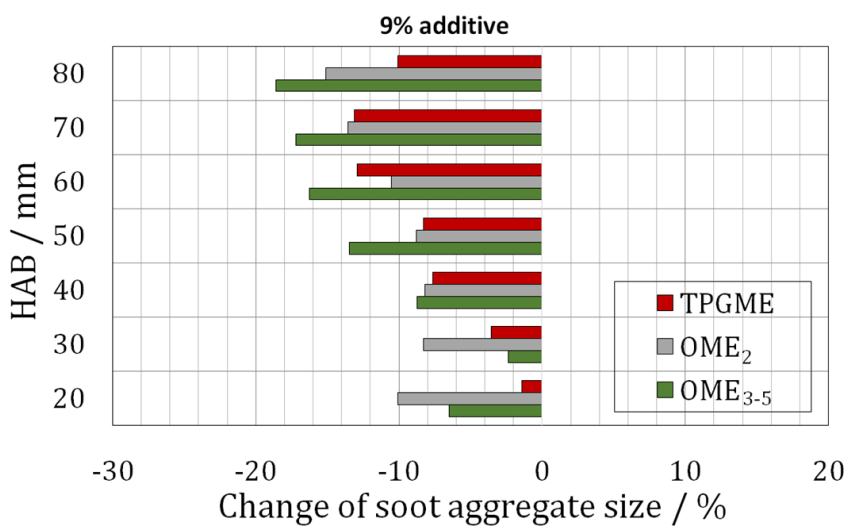

(c)

Figure 10. Comparison of $\mu_{\mathrm{g} \text {,eff }}$ change between TPGME, $\mathrm{OME}_{2}$ and $\mathrm{OME}_{3-5}$ diesel blends with respect to the baseline with (a) 1\% of additives, (b) 3\% of additives and (c) $9 \%$ of additives. 


\section{Conclusions}

The effect of TPGME, $\mathrm{OME}_{2}$ and $\mathrm{OME}_{3-5}$ on soot properties was investigated in a laminar diesel diffusion flame by two-color pyrometry, laser-induced incandescence and wide-angle light scattering. The additives were mixed with pure diesel (baseline diesel) in different concentrations, namely $1 \%, 3 \%$, and $9 \%$ vol. Eventually, the results were compared with those obtained from the measurements on the baseline diesel.

The results can be summarized as follows:

- We observe a small effect of the oxygenated additives on soot temperatures, temperature is reduced between $20 \mathrm{~K}$ and $70 \mathrm{~K}$ compared to the one found for the baseline diesel combustion.

- There is a significant reduction in soot emissions from pure diesel blended with $\mathrm{OME}_{2}$, $\mathrm{OME}_{3-5}$ (at every concentration) and 9\% of TPGME. When TPGME is inserted in a lower concentration the effects become insignificant. This TPGME-diesel blend shows a maximum decrease in soot volume fraction of $24 \%$ ( $9 \%$ vol, $70 \mathrm{~mm} \mathrm{HAB})$ with respect to the baseline diesel. $\mathrm{OME}_{2}$ and $\mathrm{OME}_{3-5}$ exhibit a maximum soot reduction of $28 \%$ and $37 \%$, respectively, for $3 \%$ vol at $90 \mathrm{~mm}$ HAB.

- Similarly, $\mathrm{OME}_{2}$ and $\mathrm{OME}_{3-5}$ show a significant effect in the reduction in aggregate size, for the highest positions measured it amounts up to $15 \%$ and $18 \%$, respectively; a pronounced effect for TPGME can only be seen for the highest concentration used of $9 \%$. The according reduction in aggregate volume/mass, when taking the fractal structure into account, roughly corresponds to the reduction in volume fraction.

We can conclude that $\mathrm{OME}_{3-5}$ has the highest impact on soot volume fraction and aggregate size from diesel combustion. $\mathrm{OME}_{2}$ also affects soot emissions, yet, to a smaller extent. OMEs emerge as promising soot-reducing additives for diesel combustion. TPGME has a controversial behavior: at lower concentration, it does not seem to influence soot production, while for an increased concentration of $9 \%$ vol, a slight reduction effect on soot volume fraction and aggregate size becomes apparent. In the majority of soot formation models the formation rate and oxidation of soot is dependent on a kinetic constant (which in turn is dependent on the temperature) and the concentration of the reagents. In our case, we find that the overall production of soot is mainly inhibited by $\mathrm{OME}_{3-5}$, the additive with the longer $\mathrm{CH}_{2}-\mathrm{O}$ chain and thus a higher oxygen content. At the same time, the temperature does not vary significantly. It is therefore possible to infer that the reduction effect observed for OMEs is probably due to their higher oxygen content. Nevertheless, further measurements on soot precursor species as well as detailed soot formation models are required to better understand the mechanism behind the effect of oxygenated additives on soot emissions from diesel.

Author Contributions: L.Z. and S.W. acquired funding for the project, N.P., L.Z., F.J.T.H. and S.W. developed the concept and measurement approach; N.P. and F.J.T.H. implemented the optical set-ups; N.P. performed the experiments; N.P. and F.J.T.H. performed the data evaluation; N.P., L.Z., F.J.T.H. and S.W. wrote the paper. All authors have read and agreed to the published version of the manuscript.

Funding: The financial support from the European Union's Horizon 2020 research and innovation programme under the Marie Skłodowska-Curie grant agreement No. 675528 (Project: IPPAD) is gratefully acknowledged. We acknowledge support by Deutsche Forschungsgemeinschaft and Friedrich-Alexander-Universität Erlangen-Nürnberg (FAU) within the funding programme Open Access Publishing.

Institutional Review Board Statement: Not applicable.

Informed Consent Statement: Not applicable.

Acknowledgments: The authors thank Benjamin Wulf Klevansky, Mijo Tvrdojevic and Simon Aßmann for supporting the measurements and post-processing. Furthermore, the authors thank Afton ${ }^{\circledR}$ Chemicals for the supply of the baseline diesel and the Lehrstuhl für Thermodynamik of Technische Universität Kaiserslautern for providing us with the OMEs additives.

Conflicts of Interest: The authors declare no conflict of interest. 


\section{References}

1. Schwartz, J. Air pollution and daily mortality: A review and meta analysis. Environ. Res. 1994, 64, 36-52. [CrossRef]

2. Stöber, W.; Abel, U.R. Lung cancer due to diesel soot particles in ambient air? Int. Arch. Occup. Environ. Health 1996, 68, S3-S61. [CrossRef] [PubMed]

3. Bond, T.C.; Doherty, S.J.; Fahey, D.; Forster, P.; Berntsen, T.; DeAngelo, B.; Flanner, M.; Ghan, S.; Kärcher, B.; Koch, D. Bounding the role of black carbon in the climate system: A scientific assessment. J. Geophys. Res. Atmos. 2013, 118, 5380-5552. [CrossRef]

4. Khalife, E.; Tabatabaei, M.; Demirbas, A.; Aghbashlo, M. Impacts of additives on performance and emission characteristics of diesel engines during steady state operation. Prog. Energy Combust. Sci. 2017, 59, 32-78. [CrossRef]

5. Gairing, M.; Marriott, J.; Reders, K.; Reglitzky, A.; Wolveridge, P. The Effect of Modern Additive Technology on Diesel Fuel Performance; SAE Technical Paper 950252; SAE International: Warrendale, PA, USA, 1995.

6. Batt, R.J.; McMillan, J.A.; Bradbury, I. Lubricity Additives-Performance and No-Harm Effects in Low Sulfur Fuels; SAE Technical Paper 961943; SAE International: Warrendale, PA, USA, 1996.

7. Barbour, R.; Arters, D.; Dietz, J.; Macduff, M.; Panesar, A.; Quigley, R. Diesel Detergent Additive Responses in Modern, High-Speed, Direct-Injection, Light-Duty Engines; SAE Technical Paper 2007-01-2001; SAE International: Warrendale, PA, USA, 2007.

8. Reid, J.; Burgess, V. Fuel Composition Comprising Detergent and Quanternary Ammonium Salt Additive. Patent WO2011110860A1, 15 September 2011.

9. Lemaire, R.; Bejaoui, S.; Therssen, E. Study of soot formation during the combustion of Diesel, rapeseed methyl ester and their surrogates in turbulent spray flames. Fuel 2013, 107, 147-161. [CrossRef]

10. Cheung, C.; Zhu, L.; Huang, Z. Regulated and unregulated emissions from a diesel engine fueled with biodiesel and biodiesel blended with methanol. Atmos. Environ. 2009, 43, 4865-4872. [CrossRef]

11. Wang, H.; Reitz, R.D.; Yao, M.; Yang, B.; Jiao, Q.; Qiu, L. Development of an n-heptane-n-butanol-PAH mechanism and its application for combustion and soot prediction. Combust. Flame 2013, 160, 504-519. [CrossRef]

12. Omidvarborna, H.; Kumar, A.; Kim, D.-S. Recent studies on soot modeling for diesel combustion. Renew. Sustain. Energy Rev. 2015, 48, 635-647. [CrossRef]

13. Wu, F.; Wang, J.; Chen, W.; Shuai, S. Effects of Different Biodiesels and Their Blends with Oxygenated Additives on Emissions from a Diesel Engine; SAE Technical Paper 2008-01-1812; SAE International: Warrendale, PA, USA, 2008.

14. Buyukkaya, E.; Benli, S.; Karaaslan, S.; Guru, M. Effects of trout-oil methyl ester on a diesel engine performance and emission characteristics. Energy Convers. Manag. 2013, 69, 41-48. [CrossRef]

15. Huang, H.; Zhou, C.; Liu, Q.; Wang, Q.; Wang, X. An experimental study on the combustion and emission characteristics of a diesel engine under low temperature combustion of diesel/gasoline/n-butanol blends. Appl. Energy 2016, 170, $219-231$. [CrossRef]

16. Schönborn, A.; Ladommatos, N.; Williams, J.; Allan, R.; Rogerson, J. The influence of molecular structure of fatty acid monoalkyl esters on diesel combustion. Combust. Flame 2009, 156, 1396-1412. [CrossRef]

17. Iannuzzi, S.E.; Barro, C.; Boulouchos, K.; Burger, J. POMDME-diesel blends: Evaluation of performance and exhaust emissions in a single cylinder heavy-duty diesel engine. Fuel 2017, 203, 57-67. [CrossRef]

18. Härtl, M.; Seidenspinner, P.; Jacob, E.; Wachtmeister, G. Oxygenate screening on a heavy-duty diesel engine and emission characteristics of highly oxygenated oxymethylene ether fuel OME1. Fuel 2015, 153, 328-335. [CrossRef]

19. Hackbarth, K.; Haltenort, P.; Arnold, U.; Sauer, J. Recent progress in the production, application and evaluation of oxymethylene ethers. Chem. Ing. Tech. 2018, 90, 1520-1528. [CrossRef]

20. Mansurov, Z. Soot formation in combustion processes. Combust. Explos. Shock Waves 2005, 41, 727. [CrossRef]

21. Johansson, K.; Head-Gordon, M.; Schrader, P.; Wilson, K.; Michelsen, H. Resonance-stabilized hydrocarbon-radical chain reactions may explain soot inception and growth. Science 2018, 361, 997-1000. [CrossRef]

22. Farrell, J.; Cernansky, N.; Dryer, F.; Law, C.K.; Friend, D.; Hergart, C.; McDavid, R.; Patel, A.; Mueller, C.J.; Pitsch, H. Development of An Experimental Database and Kinetic Models for Surrogate Diesel Fuels; SAE Technical Paper 2007-01-0201; SAE International: Warrendale, PA, USA, 2007.

23. Michelsen, H.; Schulz, C.; Smallwood, G.; Will, S. Laser-induced incandescence: Particulate diagnostics for combustion, atmospheric, and industrial applications. Prog. Energy Combust. Sci. 2015, 51, 2-48. [CrossRef]

24. Oltmann, H.; Reimann, J.; Will, S. Wide-angle light scattering (WALS) for soot aggregate characterization. Combust. Flame 2010, 157, 516-522. [CrossRef]

25. Levendis, Y.A.; Estrada, K.R.; Hottel, H.C. Development of multicolor pyrometers to monitor the transient response of burning carbonaceous particles. Rev. Sci. Instrum. 1992, 63, 3608-3622. [CrossRef]

26. Lee, W.; Na, Y.D. Soot study in laminar diffusion flames at elevated pressure using two-color pyrometry and Abel inversion. Jsme Int. J. Ser. B Fluids Therm. Eng. 2000, 43, 550-555. [CrossRef]

27. Choi, M.; Hamins, A.; Mulholland, G.W.; Kashiwagi, T. Simultaneous optical measurement of soot volume fraction and temperature in premixed flames. Combust. Flame 1994, 99, 174-186. [CrossRef]

28. Haynes, B.S.; Wagner, H.G. Soot formation. Prog. Energy Combust. Sci. 1981, 7, 229-273. [CrossRef]

29. Haynes, B.; Wagner, H.G. The surface growth phenomenon in soot formation. Z. Phys. Chem. 1982, 133, 201-213. [CrossRef]

30. Bockhorn, H. Soot Formation in Combustion: Mechanisms and Models; Springer: Berlin, Heidelberg, 1989. 
31. Glassman, I. Soot Formation in Combustion Processes. Symp. (International) on Combustion, 1989; Elsevier: Amsterdam, The Netherlands, 1989; pp. 295-311.

32. Frenklach, M. Reaction mechanism of soot formation in flames. Phys. Chem. Chem. Phys. 2002, 4, 2028-2037. [CrossRef]

33. Imtenan, S.; Masjuki, H.; Varman, M.; Kalam, M.; Arbab, M.; Sajjad, H.; Rahman, S.A. Impact of oxygenated additives to palm and jatropha biodiesel blends in the context of performance and emissions characteristics of a light-duty diesel engine. Energy Convers. Manag. 2014, 83, 149-158. [CrossRef]

34. Wang, X.; Cheung, C.; Di, Y.; Huang, Z. Diesel engine gaseous and particle emissions fueled with diesel-oxygenate blends. Fuel 2012, 94, 317-323. [CrossRef]

35. Sadeghinezhad, E.; Kazi, S.; Sadeghinejad, F.; Badarudin, A.; Mehrali, M.; Sadri, R.; Safaei, M.R. A comprehensive literature review of bio-fuel performance in internal combustion engine and relevant costs involvement. Renew. Sustain. Energy Rev. 2014, 30, 29-44. [CrossRef]

36. Lapuerta, M.; Armas, O.; García-Contreras, R. Effect of ethanol on blending stability and diesel engine emissions. Energy Fuels 2009, 23, 4343-4354. [CrossRef]

37. Herreros, J.; Schroer, K.; Sukjit, E.; Tsolakis, A. Extending the environmental benefits of ethanol-diesel blends through DGE incorporation. Appl. Energy 2015, 146, 335-343. [CrossRef]

38. Happonen, M.; Heikkilä, J.; Aakko-Saksa, P.; Murtonen, T.; Lehto, K.; Rostedt, A.; Sarjovaara, T.; Larmi, M.; Keskinen, J.; Virtanen, A. Diesel exhaust emissions and particle hygroscopicity with HVO fuel-oxygenate blend. Fuel 2013, 103, 380-386. [CrossRef]

39. Patil, A.; Taji, S. Effect of oxygenated fuel additive on diesel engine performance and emission: A review. IOSR J. Mech. Civ. Eng. 2013, 30-35. Available online: http://iosrjournals.org/iosr-jmce/papers/RDME-Volume6/RDME-54.pdf (accessed on 10 December 2020).

40. López, A.F.; Cadrazco, M.; Agudelo, A.F.; Corredor, L.A.; Vélez, J.A.; Agudelo, J.R. Impact of n-butanol and hydrous ethanol fumigation on the performance and pollutant emissions of an automotive diesel engine. Fuel 2015, 153, 483-491. [CrossRef]

41. Zhang, Z.; Tsang, K.; Cheung, C.; Chan, T.; Yao, C. Effect of fumigation methanol and ethanol on the gaseous and particulate emissions of a direct-injection diesel engine. Atmos. Environ. 2011, 45, 2001-2008. [CrossRef]

42. Giakoumis, E.G.; Rakopoulos, C.D.; Dimaratos, A.M.; Rakopoulos, D.C. Exhaust emissions with ethanol or n-butanol diesel fuel blends during transient operation: A review. Renew. Sustain. Energy Rev. 2013, 17, 170-190. [CrossRef]

43. Yoon, S.H.; Cha, J.P.; Lee, C.S. An investigation of the effects of spray angle and injection strategy on dimethyl ether (DME) combustion and exhaust emission characteristics in a common-rail diesel engine. Fuel Process. Technol. 2010, 91, 1364-1372. [CrossRef]

44. Goto, S.; Oguma, M.; Suzuki, S. Research and Development of a Medium Duty DME Truck; SAE Technical Paper 2005-01-2194; SAE International: Warrendale, PA, USA, 2005.

45. Mueller, C.J.; Pitz, W.J.; Pickett, L.M.; Martin, G.C.; Siebers, D.L.; Westbrook, C.K. Effects of oxygenates on soot processes in DI diesel engines: Experiments and numerical simulations. Sae Trans. 2003, 964-982.

46. Westbrook, C.K.; Pitz, W.J.; Curran, H.J. Chemical kinetic modeling study of the effects of oxygenated hydrocarbons on soot emissions from diesel engines. J. Phys. Chem. A 2006, 110, 6912-6922. [CrossRef]

47. Kenney, T.E.; Gardner, T.P.; Low, S.S.; Eckstrom, J.C.; Wolf, L.R.; Korn, S.J.; Szymkowicz, P.G. Overall results: Phase I ad hoc diesel fuel test program. SAE Trans. 2001, 8-32. [CrossRef]

48. Sirman, M.B.; Owens, E.C.; Whitney, K.A. Emissions comparison of alternative fuels in an advanced automotive diesel engine. Sae Trans. 2000, 2166-2176.

49. Pellegrini, L.; Marchionna, M.; Patrini, R.; Florio, S. Emission Performance of Neat and Blended Polyoxymethylene Dimethyl Ethers in an Old Light-Duty Diesel Car; SAE Technical Paper 2013-01-1035; SAE International: Warrendale, PA, USA, 2013.

50. Iannuzzi, S.E.; Barro, C.; Boulouchos, K.; Burger, J. Combustion behavior and soot formation/oxidation of oxygenated fuels in a cylindrical constant volume chamber. Fuel 2016, 167, 49-59. [CrossRef]

51. Arnal, C.; Alfè, M.; Gargiulo, V.; Ciajolo, A.; Alzueta, M.U.; Millera, Á.; Bilbao, R. Characterization of soot. In Cleaner Combustion; Springer: Berlin/Heidelberg, Germany, 2013; pp. 333-362.

52. Altenhoff, M.; Aßmann, S.; Teige, C.; Huber, F.J.; Will, S. An optimized evaluation strategy for a comprehensive morphological soot nanoparticle aggregate characterization by electron microscopy. J. Aerosol Sci. 2020, 139, 105470. [CrossRef]

53. Kuhn, P.B.; Ma, B.; Connelly, B.C.; Smooke, M.D.; Long, M.B. Soot and thin-filament pyrometry using a color digital camera. Proc. Combust. Inst. 2011, 33, 743-750. [CrossRef]

54. Cignoli, F.; De Iuliis, S.; Manta, V.; Zizak, G. Two-dimensional two-wavelength emission technique for soot diagnostics. Appl. Opt. 2001, 40, 5370-5378. [CrossRef] [PubMed]

55. Musculus, M.P.; Singh, S.; Reitz, R.D. Gradient effects on two-color soot optical pyrometry in a heavy-duty DI diesel engine. Combust. Flame 2008, 153, 216-227. [CrossRef]

56. Walsh, K.T.; Fielding, J.; Smooke, M.D.; Long, M.B. Experimental and computational study of temperature, species, and soot in buoyant and non-buoyant coflow laminar diffusion flames. Proc. Combust. Inst. 2000, 28, 1973-1979. [CrossRef]

57. Reimann, J.; Will, S. Optical diagnostics on sooting laminar diffusion flames in microgravity. Microgravity Sci. Technol. 2005, 16, 333-337. [CrossRef] 
58. McEnally, C.S.; Pfefferle, L.D. Improved sooting tendency measurements for aromatic hydrocarbons and their implications for naphthalene formation pathways. Combust. Flame 2007, 148, 210-222. [CrossRef]

59. Das, D.D.; McEnally, C.S.; Pfefferle, L.D. Sooting tendencies of unsaturated esters in nonpremixed flames. Combust. Flame 2015, 162, 1489-1497. [CrossRef]

60. Köylü, U.O.; Faeth, G. Optical properties of soot in buoyant laminar diffusion flames. J. Heat Transf. 1994, 116, 971-979. [CrossRef]

61. Olofsson, N.-E.; Simonsson, J.; Török, S.; Bladh, H.; Bengtsson, P.-E. Evolution of properties for aging soot in premixed flat flames studied by laser-induced incandescence and elastic light scattering. Appl. Phys. B 2015, 119, 669-683. [CrossRef]

62. Shaddix, C.R.; Harrington, J.E.; Smyth, K.C. Quantitative measurements of enhanced soot production in a flickering methane/air diffusion flame. Combust. Flame 1994, 99, 723-732. [CrossRef]

63. Sorensen, C. Light scattering by fractal aggregates: A review. Aerosol Sci. Technol. 2001, 35, 648-687. [CrossRef]

64. Sorensen, C.; Cai, J.; Lu, N. Light-scattering measurements of monomer size, monomers per aggregate, and fractal dimension for soot aggregates in flames. Appl. Opt. 1992, 31, 6547-6557. [CrossRef] [PubMed]

65. Sorensen, C.; Wang, G. Size distribution effect on the power law regime of the structure factor of fractal aggregates. Phys. Rev. E 1999, 60, 7143. [CrossRef] [PubMed]

66. Altenhoff, M.; Aßmann, S.; Perlitz, J.F.; Huber, F.J.T.; Will, S. Soot aggregate sizing in an extended premixed flame by highresolution two-dimensional multi-angle light scattering (2D-MALS). Appl. Phys. B 2019, 125, 176. [CrossRef]

67. Santoro, R.; Semerjian, H.; Dobbins, R. Soot particle measurements in diffusion flames. Combust. Flame 1983, 51, 203-218. [CrossRef]

68. Puri, R.; Richardson, T.; Santoro, R.; Dobbins, R. Aerosol dynamic processes of soot aggregates in a laminar ethene diffusion flame. Combust. Flame 1993, 92, 320-333. [CrossRef]

69. Hull, P.; Shepherd, I.; Hunt, A. Modeling light scattering from diesel soot particles. Appl. Opt. 2004, 43, 3433-3441. [CrossRef]

70. Huber, F.J.T.; Will, S.; Daun, K.J. Sizing aerosolized fractal nanoparticle aggregates through Bayesian analysis of wide-angle light scattering (WALS) data. J. Quant. Spectrosc. Radiat. Transf. 2016, 184, 27-39. [CrossRef]

71. Huber, F.J.T.; Altenhoff, M.; Will, S. A mobile system for a comprehensive online-characterization of nanoparticle aggregates based on wide-angle light scattering and laser-induced incandescence. Rev. Sci. Instrum. 2016, 87, 053102. [CrossRef]

72. Oltmann, H.; Reimann, J.; Will, S. Single-shot measurement of soot aggregate sizes by wide-angle light scattering (WALS). Appl. Phys. B 2012, 106, 171-183. [CrossRef]

73. Aßmann, S.; Münsterjohann, B.; Huber, F.J.; Will, S. Droplet sizing in spray flame synthesis using wide-angle light scattering (WALS). Appl. Phys. B Lasers Opt. 2020, 126. [CrossRef]

74. Palazzo, N.; Kögl, M.; Bauer, P.; Mannazhi, M.N.; Zigan, L.; Huber, F.J.T.; Will, S. Investigation of soot formation in a novel diesel fuel burner. Energies 2019, 12, 1993. [CrossRef]

75. Maffi, S.; De Iuliis, S.; Cignoli, F.; Zizak, G. Investigation on thermal accommodation coefficient and soot absorption function with two-color Tire-LII technique in rich premixed flames. Appl. Phys. B 2011, 104, 357-366. [CrossRef]

76. Eremin, A.; Gurentsov, E.; Popova, E.; Priemchenko, K. Size dependence of complex refractive index function of growing nanoparticles. Appl. Phys. B 2011, 104, 285-295. [CrossRef]

77. Snelling, D.R.; Liu, F.; Smallwood, G.J.; Gülder, Ö.L. Determination of the soot absorption function and thermal accommodation coefficient using low-fluence LII in a laminar coflow ethylene diffusion flame. Combust. Flame 2004, 136, 180-190. [CrossRef]

78. de Iuliis, S.; Cignoli, F.; Zizak, G. Two-color laser-induced incandescence (2C-LII) technique for absolute soot volume fraction measurements in flames. Appl. Opt. 2005, 44, 7414-7423. [CrossRef]

79. Vattulainen, J.; Nummela, V.; Hernberg, R.; Kytölä, J. A system for quantitative imaging diagnostics and its application to pyrometric in-cylinder flame-temperature measurements in large diesel engines. Meas. Sci. Technol. 2000, 11, 103. [CrossRef]

80. Cheng, A.; Dibble, R.W.; Buchholz, B.A. The Effect of Oxygenates on Diesel Engine Particulate Matter; SAE Technical Paper 2002-01-1705; SAE International: Warrendale, PA, USA, 2002.

81. Vertin, K.D.; Ohi, J.M.; Naegeli, D.W.; Childress, K.H.; Hagen, G.P.; McCarthy, C.I.; Cheng, A.S.; Dibble, R.W. Methylal and MethylalDiesel Blended Fuels for Use in Compression-Ignition Engines; SAE Technical Paper 1999-01-1508; SAE International: Warrendale, PA, USA, 1999.

82. Song, K.H.; Litzinger, T.A. Effects of dimethyoxymethane blending into diesel fuel on soot in an optically accessible DI diesel engine. Combust. Sci. Technol. 2006, 178, 2249-2280. [CrossRef]

83. Kocis, D.; Song, K.; Lee, H.; Litzinger, T. Effects of dimethoxymethane and dimethylcarbonate on soot production in an optically-accessible DI diesel engine. SAE Trans. 2000, 109, 2299-2308. 